\title{
EL PENSAMIENTO POLÍTICO DE LA CONTRARREFORMA Y LA RAZÓN DE ESTADO
}

\author{
POR \\ VITTOR IVO COMPARATO ${ }^{1}$ \\ Università degli Studi di Perugia \\ vicompa@tiscali.it
}

\section{RESUMEN}

Este artículo reconstruye la historia del pensamiento político de la segunda mitad del siglo XVI a las primeras décadas del siglo XVII: un período de fuertes conflictos entre la esfera religiosa y los cambios políticos de los estados más avanzados hacia el absolutismo. El análisis de la polémica contra Maquiavelo, Bodin, y los politiques muestra como fueron cuestionados en el plano conceptual la autonomía de la política de la moral religiosa y en el plano práctico la tendencia de los estados a sustraerse del control eclesiástico. Las corrientes de pensamiento que se analizan aquí -del antimaquiavelismo a la literatura encomiástica de los gobiernos existentes, del tacitismo a la razón de Estado, hasta las escrituras críticas de la sociedad como la utopía- perfilan por un lado el esfuerzo de conservar una imagen de la política como gobierno justo, con un príncipe virtuoso, pero por el otro el inevitable compromiso con las praxis del realismo político, bien representado por la evolución del concepto de razón de Estado en Botero y en otros escritores del siglo XVII. Fue sólo con la llegada del derecho natural moderno, que puso en primer plano la cuestión del origen y los fines de la sociedad civil, que el pensamiento político se sustrajo en parte de la discusión sobre el eterno conflicto entre moral y praxis política para abrir la era de la investigación racional y científica y de los derechos individuales.

PalABRAS ClaVE: Pensamiento político, Contrarreforma, sociedad civil, Estado moderno, razón de Estado, derecho natural, utopía

\section{THE POLITICAL THOUGHT OF THE COUNTER-REFORMATION ERA AND REASON OF STATE}

\begin{abstract}
This article reconstructs the history of political thought from the sixteenth to the first decades of seventeenth century: a period of strong conflicts between the religious sphere and the political changes of the states in their trajectory towards absolutism. The analysis of the polemic against Machiavelli, Bodin and the politiques shows how it was questioned at the conceptual and practical levels the autonomy of politics from religious morality and the tendency of the states to evade ecclesiastical control respectively. The schools of thought discussed here -from anti-Machiavellism to the encomiastic literature of the existent governments, from Tacitism to the reason State, to the critical writings of the society, mainly utopia- outline on the one hand, the effort to preserve an image of politics as just government, with a virtuous prince, but on the other, the inevitable commitment to the praxis of political realism, well represented by the developments of the concept of reason of State in Botero and other writers from the seventeenth century. It was only with the arrival of Modern natural law which brought to the fore the questions of the origin and purpose of civil society, that political thought partly detached from the eternal conflict between morals and political praxis opening the era of rational and scientific research and individual rights.
\end{abstract}

KEY WORDS: Political thought, Counter-Reformation, civil society, State, reason of State, natural law, utopia

Recibido/Received 29-12-2014

Aceptado/Accepted 25-11-2015

1 Profesor emérito. Università degli Studi di Perugia. Una versión de este artículo fue publicada en A. Andreatta y A. E. Baldini (eds.), 1999, II pensiero politico. Idee teorie dottrine, II, L'età moderna: 127-168. Turín: UTET. 


\section{ANTIMAQUIAVELISMO Y POLÍTICA CRISTIANA}

"Tan pronto como el Papado ocupó firmemente el centro de la escena política italiana y Internacional", la cultura de la Contrarreforma tuvo que enfrentar el problema de elaborar una teoría del Estado y una ética política coherentes con el programa del Concilio de Trento: recuperación de las conciencias, control de la producción intelectual, educación y orientación de los gobernantes y guía de la moral práctica de las masas. ${ }^{1}$ La tradición tomista y los specula principum elaborados por el pensamiento político medieval no representaban la realidad de la nueva era, caracterizada por la consolidación de los estados absolutistas. "La Institutio de Erasmo puede ser considerada acertadamente como el último y más acabado ejemplo de la tradición del speculum principis, donde no es casualidad que los elementos realistas pierden relevancia frente a la importancia de las virtudes personales del príncipe". ${ }^{2}$ Pero para la Iglesia católica las teorías políticas que habían comenzado a responder a esta exigencia de realismo, sobre todo el pensamiento de Maquiavelo, se equivocaban al separar radicalmente la esfera política de aquella religiosa y eclesiástica. Por otra parte, como la Reforma había desafiado la autoridad del pontífice romano como cabeza de la Iglesia, igualmente Maquiavelo había juzgado negativamente la presencia del papado como Estado temporal. Desde este punto de vista, el pensamiento político de la Contrarreforma se presenta como una serie de escritos dirigidos "para restablecer el imperio de la moral tradicional, fundada en los dictados divinos positivos, rechazando toda doctrina que proclamase la autonomía de cualquier acción fuera de los preceptos religiosos". ${ }^{3}$ El de la Contrarreforma, era un programa de defensa similar a aquel usado contra las confesiones reformadas, y conducido con armas muy similares, a saber, la literatura controversista y la inclusión de las obras no deseadas en el Índice de los libros prohibidos.

Al mismo tiempo, la doble naturaleza del poder papal -esto es, ser al mismo tiempo un Estado y una autoridad espiritual para los países que permanecieron bajo la obediencia de la Iglesia romana-, y el millar de hilos que unían la vida eclesiástica a la vida política y social de los estados católicos requerían también una reflexión dirigida a recopilar y organizar teóricamente las características asumidas por la política en el curso del siglo XVI. En este segundo sentido, el pensamiento político de la Contrarreforma se identificaba con los esfuerzos realizados por los escritores para describir la verdadera naturaleza de los estados y el comportamiento efectivo de los príncipes, sin sobrepasar los confines de la doctrina oficial, o inclinándola hacia ellos con el fin de que ésta les diese cabida o justificación.

\footnotetext{
1 Prosperi, A. 1996, Tribunali della coscienza. Inquisitori, confessori, missionari, XIX. Turín: Einaudi.

2 Quaglioni, D. 1987. "Il modello del principe cristiano. Gli “specula principum” fra Medioevo e prima Età Moderna”, en V. I. Comparato (ed.) Modelli nella storia del pensiero politico: 121. Florencia: Olschki.

3 Firpo, L. 1969. "Le origini dell'antimachiavellismo", en MachiaveIlismo e antimachiavellici nel Cinquecento. Atti del convengo di Perugia. II Pensiero Politico II: 338.
}

"Maquiavelo era considerado un autor peligroso en el mundo católico. No obstante, se sabía que era leído, sobre todo, por los gobiernos y las personalidades con influencia política, como se desprendía del numero de ediciones que tuvieron sus obras". ${ }^{4}$ En 1559 su obra fue incluida en el Index Librorum Prohibitorum, pero incluso antes de esta fecha escribieron contra Maquiavelo, el cardenal Reginald Pole (Apologia ad Carolum Quintum Caesarem), el obispo portugués Jerónimo Osorio (De nobilitate christiana libri III, Florencia, 1552) y el obispo italiano Ambrogio Caterino Politi (De libris a Christiano detestandis et a Christianismo penitus eliminandis, Roma, 1552). El primero, que data de finales de los años treinta, no fue publicado sino dos siglos después, pero tanto éste como los otros dos denunciaban enérgicamente el carácter anticristiano del Príncipe y de los Discursos: Maquiavelo había negado el papel de la Providencia y reducido la religión a un instrumento de gobierno. Además había sugerido al príncipe comportamientos no sólo contrarios a la religión sino también a la humanidad y a la razón. ${ }^{5}$

Los antimaquiavelistas católicos no tenían interés en la riqueza de los análisis históricos y políticos que hacían de Maquiavelo, como había observado Bodin en su obra Methodus, el primer escritor que dijo algo nuevo sobre el Estado "después de 1200 años de barbarie". ${ }^{6}$ Se limitaban a aislar del contexto los capítulos o los pasajes en los que era más explicito el tratamiento de la política como realidad irreductible a la moral cristiana para crear una especie de paradigma negativo, que frecuentemente era sólo un pretexto para expresiones rituales de repulsa y condena. Junto a esta forma de anti-maquiavelismo nació, por consiguiente, también el "maquiavelismo", entendido como una forma de la política práctica, caracterizada por la acción utilitarista privada de escrúpulos y cuyo fin era la conquista y la conservación del poder. ${ }^{7}$ Era posible, en efecto, una fácil superposición entre este esquema y la política de príncipes en el periodo del absolutismo. Con el resultado de que las acusaciones de maquiavelismo, o los escritos dirigidos a denunciar la difusión de prácticas similares florecieron en circunstancias de fuerte tensión política, sin que la referencia a Maquiavelo fuera más allá de los capítulos más notables del Príncipe, precisamente aquellos que generaban mayor escándalo. Por ejemplo, el cardenal Pole consideraba fruto de maquiavelismo la escisión de Enrique VIII. Para los protestantes ingleses, maquiavélicos eran los católicos, especialmente los jesuitas, mientras los católicos

Birely, R. 1990. The Counter-Reformation Prince. AntiMachiavellianism or Catholic Statecraft in Early Modern Europe: 16. Chapel Hill and London: The University of North Carolina Press.

5 Ibídem.

6 Bodin, J. 1951. Methodus ad facilem historiarum cognitionem, en Oeuvres philosophiques: 167a. Paris: PUF.

7 Para una bibliografía actualizada sobre el antimaquiavelismo cfr. Baldini, A. E. 2001. "Ragion di Stato, Tacitismo, Machiavellismo e Antimachiavellismo tra Italia ed Europa nell'età della Controriforma. Bibliografia (1860-2001)", en A. E. Baldini (ed.) La ragion di Stato dopo Meinecke e Croce. Dibattito su recenti pubblicazioni, Atti del convegno internazionale di Torino 21-22 ottobre 1994, 2. Ed. actualizada: 9-33 y 229-278. Genova: Name. Idem, 2014. "Aspetti storici e teorici del Machiavellismo" en G. Lencan Stoica, y Drăgulin, S. (coord.), Noi studii asupra lui Machiavelli și machiavelismului. Abordări și istoriografie. Bucuresti: Editura Ars Docendi. 
veían encarnado el maquiavelismo en los consejeros protestantes de Isabel. ${ }^{8}$ En Francia, sobre todo, donde la sangrienta conjura contra los hugonotes de la noche de San Bartolomé (1572) fue atribuida a la reina madre Catalina de Médicis y a sus principales consejeros italianos, la acusación de "maquiavelismo" fue usada para definir no sólo un comportamiento execrable por su insidiosa crueldad, sino una constante del carácter de la política de los italianos. El primer panfleto protestante contra Maquiavelo, los Discours sur les moyens de bien gouverner... Contre Nicolas Machiavel florentin de Innocent Gentillet (1576), era la obra de un partidario del duque de Alençon, que se presentó como el paladín de la buena política nacional francesa contra los consejos "tiránicos" de los extranjeros que habían corrompido los principios de gobierno. ${ }^{9}$

Los escritos contra Maquiavelo provenientes de los ambientes eclesiásticos romanos insistían en cambio, sobre puntos fundamentales que enfatizaban el origen de la separación de la política de la moral religiosa. Esto fue así debido a que la curia estaba mucho más preocupada por los procesos de emancipación de los estados católicos del control eclesiástico, que por las manifestaciones de "maquiavelismo". De hecho, la segunda ofensiva masiva contra Maquiavelo tuvo lugar en los primeros años de la década de 1590 en Francia, cuando se constituyó en torno a Enrique IV, el partido de los politiques, defensor de la independencia del Estado de las confesiones religiosas. ${ }^{10}$ El libro de Jean Bodin, Les six livres de la république, les pareció entonces tan peligroso como las obras de Maquiavelo y fue condenado en 1591 e incluido en el Índice del 1596 entre las obras prohibidas donec corrigantur. ${ }^{11}$ El jesuita Antonio Possevino estuvo a cargo de confutar todas las obras de los hugonotes La Noue e Duplessis-Mornay, la République de Bodin, así como los escritos de Maquiavelo. En 1592 en Venecia salió un Judicium de Nouae militis Galli, Johannis Bodini, Philippi Mornaei, et Nicolai Machiavelli quibusdam scriptis, que era en realidad una antología de adversarios de la Liga católica, complementado con Maquiavelo, convocado aquí sobre todo, para confirmar que la sobrevivencia de los estados se basa, no en la fortuna y las armas, sino en la verdadera religión y la providencia de Dios. EI punto de referencia teórico para Possevino seguía siendo la concepción tomista de la política.

Entre 1593 y 1595 el oratoriano Tommaso Bozio publicó cuatro libros -De imperio virtutis, Roma, 1593; De robore bellico, Roma 1593; De ruinis gentium et regnorum, Roma, 1594; De antiquo et novo italiae statu libri quatuor adversus Machiavellum, Roma, 1595- en los cuales disputaba el concepto de fortuna, el realismo político, la crítica del rol del Papado en Italia y la concepción maquiaveliana del arte de la

8 Morris, Ch. 1969. "Machiavelli's reputation in Tudor England," en Machiavellismo e antimachiavellici nel Cinquecento. Atti del convegno di Perugia. II Pensiero Politico II: 427.

9 Mastellone, S. 1969. "Aspetti dell'antimachiavellismo in Francia: Gentillet et Languet," en Machiavellismo e antimachiavellici ne Cinquecento. Atti del convengo di Perugia. II Pensiero Politico II: 376 ss.

10 Mastellone, S. 1962. La reggenza di Maria de' Medici: 20-21. Florencia: D'Anna.

11 Crahay, R. 1981. "Jean Bodin devant la censure: la condamnation de la 'République'”. II Pensiero Politico XIV: 154-178 y Firpo, L. 1981 , "Ancora sulla condanna di Bodin." II Pensiero Politico XIV: 173-186. guerra. Pero la Curia no olvidaba al más insidioso representante de la nueva ciencia política de los estados; así, el cardenal Toledo sugirió en 1595 al escritor político Fabio Albergati (1538-1606), agente del duque de Urbino en Roma, que refutase una vez más el libro de la République. Albergati esbozó el texto titulado Antibodino, que permaneció en manuscrito y cuyo extracto pasó después a la edición de los Discorsi politici. Nei quali viene riprovata la dottrina di Gio. Bodino, e difesa quella di Aristotele (Roma, 1602). Desde la perspectiva de Albergati era "indispensable acoger nuevamente a Enrique IV (y a Francia) en el seno de la Iglesia católica, pero había que purificarlo cuidadosamente de todas las doctrinas "pestíferas" que habían acompañado de alguna manera, su imparable marcha hacia el poder, comenzando por aquellas de Bodin". ${ }^{12}$

Esta batalla contra la evolución del pensamiento político orientada a separar definitivamente las "razones" de los estados de las "razones" de las iglesias se había llevado a cabo a la luz de la noción de la política cristiana elaborada por la neoescolástica, cultivada principalmente en las universidades españolas, y destinada a tener una influencia perdurable en el pensamiento político de la Contrarreforma. Era "un regreso a la filosofía de Santo Tomás, restaurada de sus decadentes expresiones del medievo tardío, pero también innovada e integrada, sobre todo por parte de los jesuitas, con una cierta libertad, y frecuentemente no sin concesiones a las instancias del voluntarismo". ${ }^{13}$ Ya en las Relectiones theologicae (1567) de Francisco Vitoria (1492-1546), notable sobretodo como precursor de la teoría del derecho internacional, se presentan los temas políticos recurrentes de la neoescolástica. El origen de la sociedad, como enseña Aristóteles, es natural, pero la forma del gobierno depende de la voluntad de la colectividad: "el poder es confiado al rey de la respublica, de la comunidad, y el rey, aunque tenga el poder de hacer las leyes, después queda vinculado por esas leyes que él mismo ha hecho" ${ }^{14}$ Por otra parte, la ley humana positiva no era, para los tomistas de Salamanca más que una interpretación, una adaptación del derecho natural (Domingo de Soto, De iustitia et iure, 1553-1554). Y el derecho natural, aunque en principio era considerado como la voluntad de Dios, era considerado un derecho racional, autosuficiente en sus prohibiciones. El contractualismo de Luis de Molina (1535-1600) era fundado sobre la idea de que, según el derecho natural, las comunidades confían el poder con límites y condiciones y pueden revocar el mandato si tales límites y condiciones no son respetados por el soberano (De iustitia et iure, 1593-1600). No se trata del derecho natural moderno: la comunidad es concebida como cuerpo y no como un conjunto de individuos titulares de derechos. Además, el titular efectivo del juicio en caso de que la autoridad temporal violase los principios del bien común y pusiese en peligro la salvación espiritual de la comunidad no era el pueblo, sino el Papa, que era el único que podía deponer

12 Baldini, A. E. 1997. "Albergati contro Bodin. Dall'Antibodino ai Discorsi politici". II Pensiero Politico XXX: 303. Cfr., también Comparato, V. I. 2013. "Readers of Bodin in Italy. From Albergati to Filangieri", en A. Howell Lloyd, (ed.) The reception of Bodin: 345-346. Leiden: Brill.

13 Fassò, G. 1968. Storia della filosofia del diritto, vol. II, L'età moderna: 77. Bolonia: II Mulino.

14 Ibídem: 81. 
al rey y privarlo de sus reinos. El jesuita Juan de Mariana (1536-1623) avanza los principios constitucionalistas definiendo tiránico todo poder legibus solutus. Consiguió con esto la aprobación del asesinato de Enrique III y en general la admisión del tiranicidio, lo que ha llevado a definir a teóricos como Mariana "monarcomacos" católicos.

La obra De rege et regis institutione de Mariana (1594) era parte de la lucha intelectual -que acompañó a aquella militar-conducida por la Liga católica de Felipe II y el Papa contra Enrique IV, antes de su conversión y absolución pontificia. Pero la cuestión general planteada en el pensamiento político seguía siendo sustancialmente aquella abierta por la Iglesia con la consolidación de los estados absolutistas modernos: hasta qué punto el pontífice romano podía continuar ejerciendo "una forma especial de ejercicio del poder por encima de las fronteras estatales". ${ }^{15}$ Los monarcas católicos usaban frecuentemente la religión para sostener sus tronos, apelando al derecho divino del rey, pero en forma tal, que excluían cualquier control eclesiástico. Los intelectuales jesuitas apelaban al contractualismo medieval, pero no para introducir principios democráticos, sino para salvaguardar el poder indirecto del pontífice. Roberto Bellarmino (1542-1621) inició como escritor político con algunas de las Disputationes de controversiis Christianae fidei publicadas en Ingolstadt en 1586 y publicadas veinte veces más hasta 1721. En las controversiae III, IV y V Bellarmino, el aún profesor del Colegio Romano de la Compañía de Jesús, trató ahí respectivamente los temas: "de Summo Pontifice militanti Ecclesiae", "de Conciliis et Ecclesia militante" y "de membris Ecclesiae militantis", anticipando el tema político que fue el tema central de toda su producción, especialmente en el libro escrito contra el absolutista William Barclay: De potestate Summi Pontificis in rebus temporalibus adversus Gulielmum Barclaium (Roma, 1610); se trata de la teoría del poder indirecto del Papa sobre los reinos terrenales. En polémica con la teoría del derecho divino del rey, Bellarmino sostenía que sólo la potestad del Papa derivaba inmediatamente de Dios, mientras que el poder de los príncipes era de origen divino, en el sentido en el que Dios quería que los hombres estuvieran sujetos a un poder político. Esto es, que los hombres se procuraran magistrados a quienes obedecer. ${ }^{16}$ Cuando a juicio del Papa un monarca ponía en peligro la salvación de las almas, el Papa tenía derecho de deponerlo y de atribuir el reino a otros príncipes, o de suscitar una nueva elección, si se trataba de un reino electivo. Contra la objeción de Barclay que afirmaba que de este modo, príncipes y monarcas se hubieran encontrado con que ejercían un poder precario y sometido a un poder temporal superior, Bellarmino oponía decididamente la siguiente tesis: el pontífice no atribuye los reinos terrenos, salvo aquellos que dependen de él según el derecho feudal. Ejercita una tutela incuestionable desde el punto de vista de la "salus animarum" y se mueve por graves razones, no por capricho o por interés. ${ }^{17}$

\footnotetext{
15 Prosperi, A. 1996: XI.

16 Bellarmino, R. 1610. Tractatus de potestate Summi Pontificis in rebus temporalibus adversus Gulielmum Barclaium: 64. Roma: Zannetti. 17 Ibídem: 118-119.
}

En principio, la doctrina del poder indirecto y las doctrinas que habían contribuido a edificar durante el siglo XVI, el modelo del princeps legibus solutus permanecían irreconciliables, como demuestra, por ejemplo, el caso de la interdicción de Venecia de 1606. También al interior de los estados católicos se había abierto la lucha de las autoridades civiles para ganar a la esfera estatal espacios de jurisdicción ejercidos por las autoridades eclesiásticas. El uso de argumentos tan tradicionales acerca de las relaciones entre la Iglesia y los estados en la controversia anti-absolutista de 1500 y 1600 era determinado por la certeza de que el mundo moderno avanzaba a grandes pasos hacia la emancipación de la política, reduciendo proporcionalmente el peso político, moral y económico de la Iglesia en las sociedades.

\section{EL MODELO DEL PRINCIPADO Y LA SOCIEDAD}

El pensamiento político en la edad de la Contrarreforma no se limitaba exclusivamente a la defensa de los principios generales que, tomando como objetivo polémico a Maquiavelo, Bodin o Barclay, permanecen constantes en los temas, las fuentes patrísticas y en el método aristotélicotomista. Los escritores políticos de la segunda mitad del 1500 tuvieron que atender las nuevas situaciones institucionales y las condiciones en las cuales se desarrollaba de hecho la vida política en la península italiana y en los otros estados católicos. En Italia había regímenes monárquicos de origen antiguo, principados bien consolidados, y repúblicas legitimadas por la venerable antigüedad, por lo cual se daba por descontada la forma política asumida por los estados en la segunda mitad del 1500, concentrándose en el problema de la mejor forma de gobierno. ${ }^{18} \mathrm{El}$ hecho de que la Reforma, en su componente calvinista, hubiera preferido formas de gobierno republicanas, como en Suiza y en las Provincias Unidas, engendraba, en realidad, un prejuicio contrario a la república y favorable al gobierno principesco. En cuanto régimen, se le consideraba más adecuado para conservar la unidad religiosa y el respeto de las tradiciones. Por otra parte, cuando no se trataba de eclesiásticos, los escritores políticos pertenecían a categorías bien definidas, en funciones subalternas en la administración o en la diplomacia de los estados. Trabajando para sus príncipes y para sus estados, estos contribuían, con la labor encomiástica de consagrar el modelo práctico del principado y fijar el rol profesional de los agentes y consejeros del príncipe.

Pertenecen a este filón muchos tratadistas políticos recopilados por Tommaso Bozza en Scrittori politici italiani

\footnotetext{
18 Para una bibliografía sobre el pensamiento político de la Italia de la Contrarreforma cfr. Baldini y A. M Battista. A. E. 1997. "Il dibattito politico nell'Italia della Controriforma. Ragion di Stato, tacitismo, machiavellismo, utopia." II Pensiero Politico XXX: 393-439. Véase también Comparato, V. I. y D. Quaglioni. 2007. Italy, en H.A. Lloyd, G. Burges, S. Hodson (eds.), European Political Thought 1450-1700. Religion, Law and Philosophy: 55-101. Yale University Press; Von Friedeburg, R. y M. J. Seidler, "The Holy Roman Empire of the German Nation", Ibídem: 128 ss.; J. H. M. Salmon. "France". Ibídem: 479-486 y X. Gil, "Spain and Portugal". Ibídem: 489-457.
} 
dal 1550 al $1650,{ }^{19}$ que deben integrarse al trabajo de Domenico Taranto. ${ }^{20}$ Una clasificación geográfica de su proveniencia demuestra que las cortes situadas en el valle del Po, como Mantua, Parma y Ferrara, el Gran Ducado de la Toscana y el ducado de Saboya fueron centros fértiles de producción de este tipo de tratados. Atentísimos a la propaganda, los Grandes Duques Cosme I, Francisco I y Fernando I eran los modelos o en todo caso, los destinatarios de numerosos tratados políticos, comenzando por aquel del patavino Lucio Paolo Roselli, II ritratto del vero governo del príncipe dall'essempio vivo del gran Cosimo de' Medici (Venecia, 1551) y del florentino Giovanni Gualandi De optimo principe dialogus (Florencia, 1551). En 1559 otro florentino, Cosimo Bartoli, secretario del cardenal Giovanni de Médicis y luego agente político del mismo Cosme, publicó en Venecia sus Discorsi historici universali. También la obra de Francesco Lottini (1512-1572) Avvedimenti civili (Florencia, 1574) fue dedicada al Gran Duque Francisco I. ${ }^{21}$ Su teoría es aristotélica y hace raramente alguna concesión al "maquiavelismo", que por otra parte, era muy familiar a Lottini siendo agente secreto del Gran Duque. Su "buen príncipe" es aquel que sigue las virtudes (no la "virtud" maquiaveliana), que piensan en el bien de los ciudadanos, ya que por "buen gobierno entiende aquel que está hecho para beneficiar a los gobernados y por malo aquel que beneficia a los que gobiernan". ${ }^{22}$ El príncipe se debe esforzar en perseguir lo honesto, que es el fin último del poder, y ser para el Estado como un padre de familia, aún cuando no pueda emplear con los ciudadanos los modos privados y afectivos que se usan con los familiares. El príncipe es más bien la "ley viva", en el sentido que da el ejemplo de la observancia de las leyes. En el fondo, como por lo demás confirman los avvedimenti sucesivos, escritos probablemente durante sus estancias en Roma y Venecia, Lottini diseña una imagen del principado como convenía tanto al ideal de la Contrarreforma como a Cosme I y a los otros príncipes italianos: un gobierno providente y virtuoso, sobre el fondo de una vida de ciudad regulada por los estatutos, con sus normas y sus magistrados. A partir del avvedimento 177, Lottini habla ya no de "principado", sino de "Estado", utilizando el ejemplo de las repúblicas antiguas. Las consideraciones se concentran en la calidad del ciudadano participe de la vida civil o ejerciendo un rol de consejo y de gobierno. La atención no está ya en el poder personal, sino en la "ciudad", que seguía siendo para los escritores italianos, el teatro histórico de la formación de los principados.

El escrito de un secretario al servicio de Alfonso II de Este, Giovan Battista Pigna (1530-1575), titulado II principe... nel qual si discrive come debba essere il Principe Heroico, sotto il cui governo un felice popolo, possa tranquilla et beatamente vivere (Venecia 1561) nos remite, en cambio, ya sea por la

19 Bozza, T. 1949. Scrittori politici italiani dal 1550 al 1650, Roma: Edizioni di Storia e Letteratura.

20 Taranto, D. 1995. Per un repertorio bibliografico delle scritture politiche italiane della seconda metà del Seicento, en "Archivio della Ragion di Stato" 3: 5-56.

21 Bozza, T. 1949: 47-48.

22 Lottini, G. 1941. Avvedimenti civili: 7. G. Mancini (ed.), Bolonia: Zanichelli. admiración por el modelo francés, que por la dedicatoria a Manuel Filiberto de Saboya, al ámbito de la monarquía de tipo continental. I/ principe de Pigna "constituye un ejemplo típico de escrito político producido en el seno de la Contrarreforma": ${ }^{23}$ aristotelismo y platonismo político cristianizados, una estrecha relación entre política y moral, la clásica teoría de las formas de Estado buenas y malas.

Muchos escritores formados en la Italia de los principados tendían a presentar la forma monárquica del Estado no tanto como la proyección directa de la voluntad de Dios, o como la forma más natural de gobierno -como sucedía con los teóricos del absolutismo europeo- sino como una elección necesaria subsiguiente a la degeneración de la politeia o de la aristocracia. La sucesión de las formas de Estado (conversio rerumpublicarum) era utilizada para explicar y justificar el origen de los principados italianos, cuyo poder era "legitimado por la aclamación del pueblo". ${ }^{24}$ Por eso, el príncipe era esencialmente el garante de un "gobierno sabio", después de una fase de confusión y de inseguridad colectivas. De ahí la necesidad de construir el retrato de un hombre virtuoso, religioso, que garantizara y se dedicara al bien público. El príncipe habría sido sobre todo "amado", y temido sólo por espíritu de reverencia y sumisión a las leyes. Si el príncipe de Lottini deja vislumbrar un tramo de maquiavelismo ("el príncipe debe ingeniarse considerablemente para parecer bueno, o al menos no malo"), ${ }^{25}$ el de Pigna, que posee virtudes en grado heroico, no tiene necesidad de fingir para alcanzar, con amor y reverencia de los ciudadanos, el objetivo del gobierno principesco: tener los pueblos en paz y contentos.

Pero había también escritores que, para obtener cargos de secretaría con algún cardenal o diplomáticos, o para funciones más turbias de agentes, emisarios y espías, se movían en contacto con los intereses efectivos de los grandes estados europeos. Estos últimos eran portadores de un realismo, o, si se quiere, de aquél "maquiavelismo" práctico, que está constantemente presente del otro lado de la moneda de la Contrarreforma. Este doble registro del pensamiento político hacía que, de un lado, eclesiásticos y profesores continuaran sumando los suyos "a la gran cantidad de comentarios en torno al... siempre venerado Aristóteles", ${ }^{26}$ mientras, por otra parte, hombres de acción ponían la pluma al servicio de personajes o de causas interesadas, revelando, con sus elecciones y sugestiones, que creían en la verdad del dicho guicciardiano que dice "no se puede mantener estados de acuerdo con la conciencia" 27 o más brutalmente con Cosme el viejo, que los estados no se gobiernan "con padrenuestros en la mano". 28

23 Baldi, R. 1983. Giovan Battista Pigna: uno scrittore politico nella Ferrara del Cinquecento: 81. Génova: ECIG.

24 Ibídem: 91.

25 Lottini, G. 1941: 39.

26 Firpo, L. 1964. "Il pensiero politico del Rinascimento e della Controriforma", en Grande antologia filosofica, X, II pensiero della Rinascenza e della Riforma: 418. Milán, Marzorati.

27 Guicciardini, F. 1990. Ricordi, De Caprio, V. (ed.) 2,48: 66. Roma: Salerno.

28 Machiavelli, N. 2005. Istorie fiorentine, en Opere, C. Vivanti (ed.) libro VII, 6: 637. Torino: Einaudi. 
Pertenecen al primer género -aquel del comentario aristotélico- las obras de Francesco Robortello (1552), Pietro Vettori (1576), Paolo Arrighi y Antonio Scaini (1577), Felice Figliucci (1583) y Nicolò di Gozzi (1591). La eficacia del aristotelismo político, entendido como método de análisis de la política y de determinación de los fines de la comunidad, no se limita a estos escritos. En los conceptos extraídos directamente de la Política, o indirectamente del neo-aristotelismo tomístico, el pensamiento político de la Contrarreforma encontraba algunas veces armas más sólidas para definir la realidad política del tiempo y contener la tendencia a la separación de la política de la moral. La concepción naturalista del Estado, el ideal de "mediocridad" y de "tranquilidad", el concepto "armónico" de la sociedad, ${ }^{29}$ así como el paradigma médico para definir la patología de los esta$\operatorname{dos}^{30}$ siguieron siendo medios cognitivos poderosos hasta mediados del siglo XVII; y el vínculo entre el buen gobierno y esferas de las virtudes, una garantía contra la concepción absolutista del poder.

El segundo tipo de escritura política es muy distinto, también en la forma: no el tratado prolijo, sino la relación, la instrucción, el 'arbitrio'. ${ }^{31}$ Si bien Scipio di Castro, fraile de origen español siempre bajo la vigilancia del Santo Oficio, desembarcado en Roma para ganarse la vida con intrigas, no era un personaje común, sus textos son significativos y reveladores de este ámbito del pensamiento político, un tanto más difundidos y leídos que los de ámbito erudito. $\mathrm{A}$ propósito de la corte romana, escribió di Castro al duque de Terranova embajador español en la Curia: "El alma de esta corte es el disimulo, pero conviene usarlo porque de otra forma Vuestra Excelencia no adquirirá ni retendrá crédito alguno". ${ }^{32}$ El modelo de la observación realista de los hechos políticos, la "relación", instrumento bien conocido de la actividad político-diplomática, en la cual sobresalían los embajadores vénetos, se convirtió también en modelo de escritura. En 1589 salió el Thesoro politico, esto es, relationi, instruttioni, trattati, discorsi varii d'Ambasciatori pertinenti alla cognitione, et intelligenza delli stati, interessi, et dipendenze de più gran Principi del mondo (Colonia), que contenía, entre otros, diversos escritos de di Castro. Después de la publicación de los Ricordi de Guicciardini en 1576, y de las Considerationi civili sopra l'Historie di M. Francesco Guicciardini recopiladas por Nannini (1582), se difundió también el modelo de la colección aforística, mezcla de citas históricas, ejemplos modernos y consideraciones persona-

29 Nuzzo, E. 1995. “Crisi dell'aristotelismo politico e ragion di Stato. Alcune preliminari considerazioni metodologiche e storiografiche", en Baldini, A. E. (ed.), Aristotelismo politico e ragion di stato: 45. Florencia: Olschki.

30 Vasoli, C. 1995. "Il carattere "naturale" dello stato e la sua "patologia" nella tradizione politica aristotelica", en Baldini, A. E. (ed.), Aristotelismo politico e ragion di stato: 53-65. Florencia: Olschki y D’Alessio, S. 2006. "Per una nuova scienza. Medicina e politica nella prima età moderna", en Biopolitiche: 265-292. Avellino: Sellino; Id. 2015 Per un principe «medico publico». Il percorso di Pietro Andrea Canoniero, Florencia: CET.

31 Se refiere al arbitrismo, corriente de pensamiento político y económico español de los siglos XVI y XVII [N. del T.].

32 Di Castro, S. 1978. La politica come retorica, R. Zapperi (ed.): 148149. Roma: Istituto della Enciclopedia Italiana. les, que permitían evitar a los escritores políticos la carga de tener que conectar en un sistema coherente las nuevas y confusas dimensiones de la política moderna.

Además los eclesiásticos, aquellos cuya función estaba contemporáneamente en contacto con la política y la pluma eran los secretarios: secretarios de príncipes, de cardenales, de embajadores; y de hecho gran parte de los escritores políticos citados habían pasado por una experiencia similar. Pero, además, se formó una literatura específica sobre el rol de este oficio en la vida política de la segunda mitad del 1500 , diseñando -además de un perfil indirecto del poderuna suerte de figura ideal del "buen secretario", interprete e -incidentalmente- participe de la acción política reservada a los grandes. Giulio Cesare Capaccio (1589), Giovanni Battista Guarini (1594), Angelo Ingegneri (1594), Bartolomeo Zucchi (1600), Tommaso Costo (1602), Vincenzo Gramigna (1620), Panfilo Persico (1620), Gabriele Zinano (1625) son los principales escritores. Sin embargo, en // secretario de un napolitano, Giulio Cesare Capaccio (1589), la profesión aparece ya inspirada por el modelo explicito del político y del hombre de gobierno: "es por consiguiente a base de los secretos de los príncipes y de las repúblicas, cuyos asuntos trata el secretario, quien con su palabra puede componer las paces, los tumultos, remediar muchos accidentes, detener, prevenir, reprimir y cosas similares que los Estados necesitan, y con su ser educado y diestro, hombre sabio y perspicaz puede con la pluma imaginar". ${ }^{33}$ También otras profesiones de la política tuvieron, en la edad de la Contrarreforma su literatura y su sistematización paradigmática: el consejero, el cardenal, el embajador, más tarde el favorito y el ministro de Estado. El pensamiento político de la Contrarreforma registraba así la expansión y la articulación progresiva del aparato estatal, tomando en consideración las nuevas figuras de auxilio del gobierno.

Del mismo modo, a través de la literatura política especializada, se reflejaba la dialéctica entre los grupos sociales del 1500. El ideal aristotélico de la armonía ocultaba en realidad tensiones y competiciones por la primacía, o la defensa de las capas privilegiadas contra la movilidad ascendente de nuevos grupos, principalmente de juristas y ricos mercantes. ${ }^{34}$ No se puede eliminar del pensamiento político de ese periodo la vasta literatura sobre la nobleza sin reducir la imagen del Estado en el siglo XVI a una relación abstracta entre el príncipe y los súbditos que no tenía base en la realidad, ya que el poder principesco era gestionado sobre la base de un acuerdo consolidado con las aristocracias. "La principal nota distintiva de los años en torno a la mitad del siglo XVI [fue] la tendencia... hacia una más completa homogeneización ideológica de tipo nobiliario de los diversos grupos dominantes italianos. Era una tendencia que se desarrollaba paralela -y algunas veces se intersecaba- con la que estaba teniendo lugar en el campo religioso". ${ }^{35} \mathrm{En}$ el Dialogo dell'honore (1553) de Giambattista Possevino, her-

33 Capaccio, G. C. 1597. II Secretario: 1v.-2r. Venecia: Nicolò Moretti.

34 Mastellone, S. 1989. Storia del pensiero politico europeo, vol. I, Dal XV al XVIII secolo: 84-89. Turín: UTET Libreria.

35 Donati, C. 1988. L'idea di nobiltà in Italia. Secoli XIV-XVIII: 93. Roma-Bari: Laterza. 
mano del citado Antonio, emerge la idea de que la nobleza es una cosa en sí, que se transmite con la sangre y consiste en una efectiva superioridad sobre los innobles, debida no a la educación, sino a la calidad de los "espíritus" derivada de la riqueza y de la mejor alimentación. La conexión entre riqueza y nobleza -una aspiración común para los grupos mercantiles que habían pasado a ser propietarios de tierrases presentada por Possevino como un hecho natural, ${ }^{36}$ pero este nexo no era pacifico e indiscutible, desde el momento que existían tanto nobles pobres, como ricos mercantes a los que no se quería admitir en el grupo nobiliario. Entonces se elaboró un esquema de identificación que consideraba al mismo tiempo la sucesión de sangre y la historia: nobles eran aquellos que podían probar que descendían de nobles desde un periodo de tiempo suficientemente remoto para ser juzgado inmemorable. Este mecanismo favoreció el florecimiento de otro género de escritura, colateral a la escritura política -ya que también esa se situaba en la esfera del servicio a los poderosos- que fue aquel de las genealogías.

El espíritu de la Contrarreforma se había ido conjugando así con la evolución material de los estados y de las sociedades relativas, donde al final del siglo XVI resultaba indiscutible el poder principesco y se habían fijado rígidamente las jerarquías sociales. Esta tendencia tuvo respuesta también en la organización del Estado pontificio. Con Sixto V se reformó la estructura administrativa interna y la soberanía del pontífice, ya sea en el cuadro específico de un principado eclesiástico electivo, que asumió el mismo aspecto impersonal y burocrático de los otros estados. ${ }^{37}$ El principio de autoridad invadía la esfera política como aquella religiosa. Los súbditos debían ser educados en las virtudes de la obediencia, el grupo político, a su vez, en las tareas del gobierno. La orden de los jesuitas, especializados en la educación de los príncipes y de los grupos dominantes había constituido una red densa de colegios en el mundo católico y elaborado sistemas educativos fuertemente jerárquicos consagrados en la Ratio studiorum de 1599. El general superior, el cardenal Acquaviva impuso también la unidad doctrinal de la Compañía, adoptando el tomismo como filosofía oficial.

\section{EL MODELO REPUBLICANO Y LA UTOPIA}

El estado principesco, fuerte en el vértice, pero garante del dominio social de la aristocracia y de sus poderes periféricos se hace más evidente naturalmente en el pensamiento político. No obstante, el inventario de la publicística política de la segunda mitad del siglo XVI revela una serie de temas y filones de pensamiento que no son reducibles al modelo triunfante, o que se dirigen más o menos abiertamente en el sentido opuesto. El pensamiento político florentino que prosperó entre las dos repúblicas, y en particular Maquiavelo, fue durante mucho tiempo un fermento intelectual para el pensamiento político europeo capaz de leer más allá del Príncipe. El interés más profundo del

\footnotetext{
36 Ibídem: 100-101.

37 Prodi, P. 1982. Il sovrano pontefice: un corpo e due anime. La monarchia papale nella prima età moderna: passim. Bolonia: Il Mulino.
}

secretario florentino era meditar sobre las repúblicas antiguas, para entender cómo se podía hacerse una moderna que fuese duradera. Después de la caída de Siena bajo el dominio mediceo, sobrevivieron en Italia las repúblicas de Venecia, Génova, Lucca, S. Marino, con una literatura política específica, dirigida a describir y sostener la estructura republicano-oligárquica mantenida por ellas en la era de los principados. En los escritos comisionados por las republicas a sus historiadores oficiales no se exalta la forma republicana en sí, sino los méritos, la antigüedad, la solidez de aquel Estado especifico. Pero el sentimiento de la república concebida como un modo de vivir políticamente alternativo sobrevivió en la edad de la Contrarreforma, y fue frecuentemente el modo de expresar un rechazo general del espíritu del tiempo. En este sentido "vida política" es sinónimo de vida virtuosa opuesta a la vida corrupta. La vida política exige de hecho que los ciudadanos den prioridad a los intereses de la república respecto a sus intereses particulares; requiere virtudes civiles ya sea en los magistrados como en los ciudadanos". ${ }^{38}$

Después de la mitad del siglo XVI el modelo republicano ideal no se busca tanto en la república romana, sino en las repúblicas existentes, o en aquellas que se estaban formando en Europa. En la idealización de Venecia como gobierno, al mismo tiempo, libre y ordenado habían tenido gran importancia las obras de Gaspar Contarini, De magistratibus et republica venetorum (París, 1543) y sobretodo la del florentino Donato Giannotti, De la repubblica de' Viniziani (Roma, 1540). Se remonta a estos textos la sistematización conceptual de la forma del estado veneciano en el paradigma polibiano del "estado mixto", mixto de aristocracia, monarquía y democracia. También escribió a favor del republicanismo y de Venecia otro florentino, Bartolomeo Cavalcanti (1503-1562), un expatriado, decidido adversario político del principado mediceo. Sus Trattati overo discorsi... sopra gli ottimi reggimenti delle republiche antiche et moderne fueron publicados de forma póstuma en Venecia en 1571. Del interior de la república se debe señalar hacia los 70's los Concetti politici de M. Francesco Sansovino (1578), autor también de Venezia città nobilissima et singolare (1581), la Breve institutione dell'ottima republica de Jason de Nores (Venecia, 1578) y Della perfettione della vita politica de Paolo Paruta (Venecia, 1579). Esta última obra -se trata de un dialogo de estilo y sabor aún humanistaera una tranquila, pero en el fondo apasionada defensa de la necesidad de participar en la vida pública, una confirmación del ideal "civil" típico de la tradición republicana. ${ }^{39}$ De Paruta fueron publicados de forma póstuma, en 1599, los Discorsi politici, obra razonada e influyente destinada a dar al siguiente siglo un modelo republicano. Hay que tener en cuenta en la evaluación de la aportación conceptual de los Discorsi de Paruta y del Compendio universal di republica

38 Viroli, M. 1994. Dalla politica alla ragion di stato. La scienza del governo tra XIII e XVII secolo: 97. Roma: Donzelli. Sobre el repubblicanismo como corriente política y intellectual en la edad moderna: $M$. van Gelderen y Q. Skinner (eds.) 2002. Republicanism: a shared European heritage. Cambridge: Cambridge University Press, 2 vol.

39 Paruta, P. 1964. Della perfezione della vita politica, en B. Widmar (ed.) Scrittori politici del '500 e '600. Milán: Rizzoli. 
de Pier Maria Contarini, que lo sucedió a distancia de pocos años (1602), que mientras tanto, el pensamiento político europeo conoció y asimiló la distinción bodiniana entre las formas de Estado y de gobierno. "Republica" no era más un concepto unívoco, ni la definición polibiana de Estado mixto satisfactoria para calificar la naturaleza de las ciudades, que se juzgan, según Paruta, por la "comunicación con el gobierno". Roma dejaba de ser un modelo para el presente para el republicanismo de la última parte del siglo XVI, porque sus valores políticos de la guerra y la conquista ya no eran conformes con los de la armonía y la paz. "Roma fue señora del mundo; pero no por mucho tiempo, no contó con la tranquilidad de sus ciudadanos, que no pudieron disfrutar de tanta grandeza y prosperidad. Pero Venecia, aunque era un Estado menor, se había conservado como el único ejemplo de libertad, segura de todo trabajo doméstico, y con la maravillosa unión y concordia de sus ciudadanos. ${ }^{40}$ La concordia ordinum, fundamento del mito de Venecia, sobrevive en Paruta, mientras Contarini abandona del todo el vetusto esquema del Estado mixto, para aceptar el concepto de soberanía indivisible de Bodin. Por eso Venecia es francamente aristocrática y en esto reside su fuerza: "La república funda mejor su libertad en el Estado de los optimates, que reinan en buen número con autoridad limitada temporalmente, con mucho menor participación del pueblo en los lugares inferiores. Con lo que su temperamento está mucho más establecido en la libertad, más libre de disturbios civiles y más seguro contra la tiranía". ${ }^{41}$

Entre más se insistía en la función del orden del régimen veneciano, menos evidentes eran las diferencias políticas entre la Serenísima y los principados de la Contrarreforma: Contarini, en efecto, se había hecho del partido conservador, o de los "viejos". ${ }^{42}$ En realidad, al final del siglo XVI, después de un periodo de buenas relaciones con el Papado en nombre del frente común contra el Turco, creció en Italia y en la misma República la consciencia de que detrás de los crecientes contrastes con Roma "había un profundo conflicto entre dos culturas y dos concepciones de la realidad antagonistas". ${ }^{43}$ Las huellas de un sentimiento filo-republicano en Italia se pueden encontrar no sólo en la literatura de los Discorsi de Maquiavelo, sino en la elección de Venecia como meta real, o como refugio ideal de muchos tránsfugas de los estados o del clima contrarreformista, por razones religiosas o políticas. La confianza en la "libertad" veneciana, libertad privada, libertad de pensamiento, se reforzaba a la luz del sistema político internacional, que veía a Venecia colocada del lado antiespañol. ${ }^{44}$

40 Paruta, P. 1943. Discorsi politici nei quali si considerano diversi fatti illustri e memorabili di principi e di repubbliche antiche e moderne divisi in due libri, G. Candeloro (ed.): 241. Bolonia: Zanichelli.

41 Contarini, P.M. 1990. Compendio universal di republica, V. Conti (ed.): 34. Florencia: CET.

42 Conti, V. en Contarini, P.M. 1990: IX-X.

43 Bouwsma, W. J. 1977. Venezia e la difesa della libertà repubblicana. I valori del Rinascimento nell'età della Controriforma: 204. Bolonia: il Mulino.

${ }_{44}$ Spini, G. 1960. Storia dell'età moderna: II, 481-483. Turín: Einaudi. Es preciso recordar que el Colloquium heptaplomeres de Jean Bodin tiene lugar en Venecia, porque era considerado el teatro ideal para el dialogo libre entre las religiones.
La república de Génova, que en cambio prosperaba fungiendo de central financiera de España y de sus aliados, no se convirtió en modelo político, ni tuvo una literatura política de igual espesor. En 1559 Oberto Foglietta (1518-1581) publicó en Roma, donde era referendario apostolico, ${ }^{45}$ Della republica di Genova libri II, en los cuales sostenía las tesis de la nobleza "nueva" a favor de reformas antioligárquicas: lo que le valió una condena del vicario arzobispal genovés. Una vez apagadas las luchas entre partidos en 1575, Génova lo designó historiador oficial. Pero la república entraba precisamente entonces en aquella "edad indolente" ${ }^{46}$ que no podía suscitar fermentos intelectuales particulares y esperanzas de renovación.

Frente a la clausura de los regímenes políticos y al estancamiento de las relaciones internacionales, la tensión hacia la renovación tomó -aún en la era aparentemente más lejana del idealismo -la forma de la utopía, inspirada en Platón y Thomas More. En la Edad de la Contrarreforma el elemento religioso se intersecta fuertemente con el propósito de reforma social, hasta convertirse, en algunos casos, en un elemento dominante. Pero el primer texto que inaugura este filón en Italia, II mondo savio e pazzo (1552) de Anton Francesco Doni (1513-1574), está inspirado en la República platónica. En efecto, todo regreso del platonismo político, con su racionalismo y su tendencia arquitectónica, confina con el utopismo. Doni aspira a una ciudad "feliz", donde es eliminada, con la abolición de la propiedad privada, la moneda, la familia, toda causa de desigualdad y de conflicto, por lo cual no son necesarios ni el gobierno ni las leyes. Pero la inspiración de Doni no se puede decir que sea eudemonista, la vida social es geométrica y uniforme. "Feliz" debería haber sido también la ciudad de Francesco Patrizi da Cherso (1529-1597) (La città felice, Venecia 1553), aún más platónica en la inspiración política, porque en eso la igualdad de los bienes y de los privilegios es limitada sólo a la aristocracia. ${ }^{47}$ Patrizi, que había frecuentado la Universidad de Padua, había absorbido fuertes dosis de aristotelismo médico, y su modelo de ciudad resulta una combinación entre el neoplatonismo ideal de un gobierno de los sacerdotes-sapientes, y una organización productiva inspirada en el determinismo físico. ${ }^{48}$ En realidad, la felicidad de las utopías termina siempre en una forma de ascesis, que para ser alcanzada necesita de la plenitud de los "espíritus", que se resuelve después en una realización moral: "Consistiendo... la felicidad, la mejor parte y su realización, en las operaciones de la virtud, es necesario, si nuestros ciudadanos quieren ser beatos, que primero sean virtuosos". ${ }^{49}$ Los escritos de Francesco Pucci (Forma d'una republica catolica, 1581) e de Ludovico Agostini (Dialoghi

45 Funcionarios de la curia romana encargados de examinar las suplicas dirigidas al Papa, referir al mismo y predisponer las decisiones para su firma [N. del T.].

46 Costantini, C. 1978. La repubblica di Genova nell'età moderna: 142. Turín: UTET.

47 Patrizi, F. 1964. La città felice, en B. Widmar (ed.) Scrittori politici del '500 e '600: 61. Milán: Rizzoli.

48 Vasoli, C. 1987. Francesco Patrizi da Cherso e il "modello" della società dei sacerdoti-sapienti, en V. I. Comparato (ed.) Modelli nella storia del pensiero politico: 123-144. Florencia: Olschki.

49 Patrizi, F. 1964: 82. 
dell'infinito, 1585-1590) permanecieron manuscritos, pero testimonian cuanto la aspiración al universalismo religioso, ya se en forma de religión natural o en forma de cristianismo fraterno, animaban el espíritu utópico de la edad del Estado absoluto y del dominio aristocrático. De la misma manera, contra las asperezas de las guerras civiles y de religión, sobrevivía en Francia el universalismo religioso de Postel y el irenismo cristiano de Jean Hotman de Villiers.

La utopía expresa un deseo de evasión del propio tiempo, mas la huella de ese tiempo hace cada vez más evidentes los elementos contrarios a la ciudad ideal imaginada. La città del Sole de Tommaso Campanella (1568-1639) fue concebida en 1599 y escrita tal vez en 1602, cuando el fraile calabrés se encontraba en prisión por haber urdido un intento revolucionario en el reino de Nápoles. No hay duda que representa un grito de protesta contra el mal gobierno español, la opresión de los barones y la miseria de las masas campesinas. Pero, al mismo tiempo, ésta manifiesta claramente el espíritu de un "intelectual eclesiástico" de la Contrarreforma, ${ }^{50}$ que retoma elementos platónicos para designar una sociedad comunista gobernada por sacerdotes-sapientes. La Città del Sole es ella misma una enciclopedia del saber, representada visiblemente en sus muros. Los Solarianos conducen una vida regulada, bajo el gobierno ilustrado del Sacerdote-Sol y de sus oficiales Pon, Sin, Mor. Visten de la misma forma, toman sus comidas en común, se entrenan para la guerra y para sus respectivas ocupaciones. La utopia previene la aparición de los males del siglo, excluyendo el uso del dinero, el ocio y la acumulación de la riqueza. Los matrimonios son regulados según los principios de eugenesia astrológica del naturalismo filosófico hermético absorbido por Campanella en su formación juvenil. El espíritu universalista y teocrático que se puede leer en el fondo de este diseño de ciudad filosófica tomará forma más explícita en la Monarchia Messiae, donde Campanella, también con el propósito de recuperar el favor de las autoridades de las que dependía su liberación, tejió el elogio del gobierno papal: gobierno perfecto, porque está mezclado con la democracia, aristocracia y monarquía, y es por tanto capaz de "traer de vuelta el siglo de oro, cuando en el mundo habrá una ley universal conforme a la ley de la naturaleza". ${ }^{51}$

\section{POLÍTICA Y MORAL. EL TACITISMO}

Las aspiraciones universalistas podían entonces reincorporarse-tanto así en el ambiguo naturalismo de Campanellaen la teología política de la Contrarreforma en su forma "absoluta", y estar en fuerte contradicción con otro aspecto del pensamiento político del tiempo, aquel que buscaba acomodarse con el realismo político. Según Toffanin, Tácito era una lectura más confesable que Maquiavelo y sirvió de sustituto del secretario florentino para tomar nota de las acciones efectivas de los gobernantes y discutir los aspectos

50 Crahay, R. 1993. Un intellectuel ecclésiastique au xvII siècle: Tommaso Campanella, Perugia: Dipartimento di scienze storiche.

51 Mastellone, S. 1989: I, 79. más ambiguos de la "prudencia política".52 Pero en la historia de la cultura política de la Contrarreforma el tacitismo no es simplemente una pantalla del maquiavelismo. Después de la edición crítica de las obras editadas por Justus Lipsius (Leiden, 1576), la lectura de los Annales había pasado decididamente de los historiadores a los políticos. ${ }^{53}$ Los nuevos tiempos de las guerras civiles eran advertidos, escribía Montaigne en los Essais, como un estat trouble et malade, ${ }^{54}$ y para ellos la lectura de Tácito coincidía por la similitud de situaciones y por analogía de método. Los comentaristas italianos, franceses, ingleses, flamencos y españoles encontraron adecuado a las nuevas exigencias de la política el realismo tacitiano, junto con el moralismo. Leído como colección de máximas de ejemplos políticos, Tácito podía dar respuesta a las preguntas de actualidad: ¿hasta dónde llega el deber de los príncipes de tener fe en las promesas? ¿Cuándo la crueldad mal empleada se vuelve contra ellos? Tácito tenía el merito de describir objetivamente las situaciones con un lenguaje sintético y tajante. Su condena del principado romano era evidente para quien quisiera recogerla (como había hecho Guicciardini y haría nuevamente Trajano Boccalini al inicio del siglo XVII), pero la mayoría de los comentaristas del quinientos y seiscientos prefirieron leer en su relato los signos de la naturaleza ordinaria del poder, y usarlo como colección de preceptos.

El éxito de la historiografía tacitiana como fuente de conocimiento de la política era una prueba del escepticismo sobre la posibilidad de definir en forma unívoca la esfera pública, pero también el síntoma de la insatisfacción por los métodos de reflexión sobre el poder fundados en la teología, en el derecho o en modelos clásicos de Aristóteles y Platón. Tácito sustituye a Aristóteles porque la dialéctica del ejercicio del poder en Aristóteles y en los escolásticos tiene como horizonte la civitas y en Tácito la corte. Tácito consiente introducir en el análisis político la psicología individual, el juego de los intereses y de las pasiones, mientras en la sociedad inspirada del ideal del príncipe cristiano o del modelo "civil" el espacio individual es secundario y las virtudes son públicas. La dedicación al bien común es un deber no menos para el príncipe que para los cives de una república libre. En cambio, en la sociedad autoritaria de finales del siglo XVI las personalidades de los "Grandes" que recitan los dramas del poder se destacan sobre la escena pública con sus cálculos y movimientos personales, luchas subterráneas, disimulaciones y decisiones. Decisiones que cambian el curso de la historia y el destino de los hombres. Esta variable no era ignota a la ciencia política tradicional, pero ciertamente no había recibido la misma consideración y peso que tuvo en tiempos modernos, cuando matizada la distinción aseguradora entre los actos del buen príncipe y aquellos

52 Toffanin, G. (1921) 1972. Machiavelli e il "Tacitismo". La "Politica storica" al tempo della controriforma: 129. Nápoles: Guida.

53 En la introducción a la traducción italiana de los Politicorum libri duo de Lipsius Tiziana Provvidera describe claramente la importancia de la labor filológica de Lipsius en la transición del aristotelismo a la razón de Estado: Lipsio, G. 2012. Opere politiche, vol. I, La Politica, T. Provvidera (ed.), con un ensayo de M. Fumaroli. Torino: Nino Aragno.

54 Montaigne, M. de 1962. Essais, en Oeuvres complètes, III, 8: 920. Paris: Gallimard. 
del tirano -siendo casi imposible para el hombre común el conocimiento de las intenciones-, a los escritores políticos, nos les quedaba más que buscar entre los intereses (racionales) y las pasiones (irracionales) de los poderosos.

En cambio, a los príncipes servía como una especie de manual técnico. El historiador de las guerras civiles de Francia, Enrico Caterino Davila, recuerda que Tácito era una de las lecturas preferidas de Enrique III. ${ }^{55}$ Uno de los primeros comentarios a Tácito se hizo debido a un consejero italiano de Enrique III, Carlo Pascale (París, 1581), que lo dedicó a Carlos Manuel de Saboya. Annibale Scotti, autor de Commentarii a Tacito, ad politicam et aulicam rationem praecipue spectantes (Roma, 1589) había estado al servicio de Ottavio Farnese y era, en aquel año, camarero secreto de Sixto V. Scipione Ammirato mientras escribía sus Discorsi... sopra Cornelio Tacito, dedicados a la Gran Duquesa Cristina de Lorena (Florencia, 1594) estaba al servicio del Gran Duque como historiador y genealogista. El mantuano Filippo Cavriana (1536-1606), autor de los Discorsi... sopra i primi cinque libri di Cornelio Tacito (Florencia, 1597) había estado en Francia donde fue médico de Catalina de Médicis, agente secreto del Gran Duque y había regresado justo a tiempo a Florencia acompañando a Cristina de Lorena en 1589. El Seminario de' governi di stato, et di guerra (Venecia, 1613), colección de 2000 máximas sobre Tácito, era una obra de otro agente secreto, Girolamo Frachetta (1558-1609), literato formado en la escuela aristotélica de Piccolomini, pero informador al servicio de los españoles y más tarde del duque de Urbino. ${ }^{56}$

No todos los comentaristas de Tácito tuvieron esta característica especial, de tener relaciones cercanas con los arcana imperii durante el periodo que duró la moda tacitista, y que fue toda la primera mitad del siglo XVII, contagiando eclesiásticos y profesores. Pero no hay duda de que, los Annales fueron usados como un espejo de la praxis política, útil para aprender las astucias de Tiberio, sin que fuera un modelo para los soberanos. Decía Cavriana que Tácito había escrito como si hubiera sido un secretario de Estado. Por otra parte, tantas acciones individuales disimuladoras juzgadas por el criterio de la eficacia no corrían el riesgo de componer la imagen del tirano, mientras que él se había mantenido intacto en el modelo general del príncipe cristiano: lo que no era posible usando a Maquiavelo. El pensamiento político de la Contrarreforma encontraba así en Tácito la posibilidad de ir más adelante en el registro de la praxis política sin tener que revisar el esquema general.

\section{LA RAZÓN DE ESTADO COMO CIENCIA POLÍTICA: BOTERO}

No es que no hubiera necesidad de un nuevo esquema general, sobre todo considerando que los tratados sobre el príncipe de una sola edición, pagada por el mecenas del momento, o los comentarios a Aristóteles no cruzaban los

55 Davila, E. C. 1683. Historia delle guerre civili di Francia: 275 Venecia: Prosdocimo.

56 Baldini, A. E. 1989. "Le guerre di religione francesi nella trattatistica italiana della ragion di Stato: Botero e Frachetta". I/ Pensiero Politico XXI: 301-324. confines del principado o los umbrales de la universidad. Hacía falta una forma de comunicación dirigida a un público europeo, que tuviera en cuenta el escenario europeo de las últimas décadas del siglo. Desde el punto de vista de un escritor de la Contrarreforma, había dos cuestiones abiertas: la revuelta de las Provincias Unidas con el Rey católico Felipe II y la batalla de Francia entre la Liga católica apoyada por España y el legítimo sucesor al trono, el hugonote Enrique de Navarra. Entre 1588 y 1594, frente a la masacre de Blois, la insurrección de París, después el asesinato de Enrique III y la sucesión de Enrique IV, en la Curia romana se manifestó -ya sea en forma disimulada e indirecta, propia de los partidos de la Curia- una ventaja de posiciones políticas, que iban de la absoluta intransigencia de la facción filo-española al posibilismo de muchos prelados filo-franceses y del mismo Sixto V. ${ }^{57}$ Pero esta cuestión preocupaba, precisamente en el momento en el que podía perfilarse el acuerdo, que el mundo católico debía rendirse a las tesis de los politiques, representados por la République de Bodin, y no disponían de un libro de política adecuado. Escribía monseñor Minuccio Minucci en 1588: "Estos estudios políticos de un tiempo acá aumentan mucho la estima, ningún hombre en el mundo piensa poder ganar honor en el mundo si no entiende las razones de Estado... y así como aquello que quieren seguir estas curiosidades, no se puede tomar entre las manos un libro bueno que con método y cierta facilidad un hombre político cristiano, se pueda formar y aprender seguramente o al menos darse una idea de tales ciencias". ${ }^{58}$

En los años 80 se estaba formando entre los intelectuales católicos una exigencia similar. El piamontés Giovanni Botero (1544-1617) al ser obligado a abandonar en 1580 la Compañía de Jesús, por desacuerdos con sus superiores entró al servicio del cardenal de Milán Carlos Borromeo. En 1583 publicó en Milán su primer obra política, De regia sapientia. En la dedicatoria a Carlos Manuel I de Saboya explicaba que su motivación para escribir esta obra venía de una conversación sobre la reciente revuelta de las Provincias Unidas, en la cual los interlocutores parecían estar de acuerdo con Maquiavelo "que el rey no debía forzar dentro de los límites marcados por el evangelio los principios rectores de su conducta política, si quiere que su autoridad perdure intacta". ${ }^{59}$ Botero sostenía naturalmente la tesis opuesta, pero es importante notar como el nuevo antimaquiavelismo de finales del siglo XVI nacería no del enésimo pensamiento de las tesis del Príncipe, sino de los hechos internacionales. Una vez al servicio de Carlos Manuel I, Botero fue enviado en 1585 a Francia para una misión en la Ligue, donde leyó la République de Bodin; posteriormente, regresó primero a Milán y luego a Roma como agente y secretario de Federico Borromeo, gracias a su experiencia diplomática directa. En Roma Botero terminó sus mejores obras, Delle cause della grandezza delle città, Della ragion di stato, las Relazioni universali.

\footnotetext{
57 Baldini, A. E. 1995: 202 ss.

58 Baldini, A. E. 1995: 206.

59 Firpo, L. 1990. La "Ragion di Stato" di Giovanni Botero. Redazione, rifacimenti, fortuna", en G. Botero, Della ragion di stato $e$ Delle cause della grandezza delle città: 3-4. Bolonia: Forni (reprint de
} l'ed. de Venecia, 1598). 
La Ragion di stato apareció en Venecia en 1589: era una reconsideración de los temas del De regia sapientia, y había sido inspirada a propósito de combatir el maquiavelismo y de confirmar la estrecha dependencia de todo poder político de la religión y de la Iglesia. Sin duda alguna, la experiencia francesa y el conocimiento de la Roma de Sixto V, hicieron su efecto en la obra de Bodin. En la Ragione se percibe "el aliento de experiencias objetivas, el dato experimental que rompe el prejuicio de lo abstracto, la realidad de los problemas económicos y sociales... que emerge de la cáscara de los esquemas edificantes" ${ }^{60}$ En su propósito y en su estructura, la obra de Botero respondía bien al deseo de Minucci: era algo sistemático, pero ágil (los diez libros superaban apenas las trecientas páginas en 8으), no tenía un modelo principesco estrechamente italiano, sino la forma-"Estado" dominante en la Europa del tardo siglo XVI: el Estado monárquico absoluto. La obra estaba después, voluntariamente, orientada a emancipar la ciencia política -adoptando un sistema clasificatorio diverso- de los esquemas de Maquiavelo y de Bodin: por ejemplo, la tipología de los dominios es un intento obvio de diluir en una pluralidad de situaciones las secas alternativas maquiavelianas (o republicas, o principados, y los principados o antiguos o nuevos). La definición del Estado -“Estado es un dominio firme sobre los pueblos"- es el eco del concepto de soberanía bodiniano, pero sin sustancia jurídica, e inmediatamente explicada para definir el único caso del principado. El tercer propósito de Botero -el más ambicioso- era recoger en un tratado toda la literatura política que en el curso de siglo XVI describió y debatió la política efectiva de los estados, que habían actuado realísticamente en el plano del arte político, de los intereses y del secreto, esto es, de la razón de Estado, que en el lenguaje común italiano significaba precisamente todo esto.

Pero Botero define la razón de Estado como notitia di mezi atti a fondare, conservare, e ampliare un Dominio. ${ }^{61}$ Esta notitia -esto es, conocimiento, sabiduría- fue la primer señal de la intención del jesuita piamontés de cambiar el estatus de la razón de Estado, considerada una práctica política inmoral y sin escrúpulos, para llevarla a la esfera objetiva, dándole un estatus neutral. La razón de Estado, afirmaba Botero, "supone el príncipe y el Estado (el primero casi como creador y el segundo como materia)." Se llama "razón de Estado" todo eso que sirve para fundar, ampliar y conservar un dominio ¿pero en realidad cuál es la tarea más difícil y gloriosa de un príncipe? Sin duda conservar, porque los asuntos humanos por naturaleza a veces crecen y otras faltan, y es difícil alcanzar la estabilidad. Se ha dicho que la razón de Estado es el texto principal de la afirmación del "paradigma conservador" en los orígenes de la modernidad política. ${ }^{62}$ El fin de la política es, de hecho, para Botero la conservación del Estado y la conservación consiste "en la tranquilidad y la paz de los súbditos". ${ }^{63}$ Es más fácil que

\footnotetext{
60 Ibídem: 5.

61 Botero, G. 1990. Della ragion di stato e Delle cause della grandezza delle città: 1. Bolonia: Forni, (reprint de la ed. de Venecia, 1598).

62 Borrelli, 1993, 63 ss.

63 Botero, G. 1990: 15.
}

este objetivo se alcance en los estados "medianos", no muy pequeños que no puedan resistir a la agresión extrajera, ni muy grandes y ricos sometidos a la envidia de los demás. En todo eso que es mediano hay, aristotélicamente, para Botero algo tranquilizador; las pasiones son menos fuertes: la ambición, el deseo, la envidia, la sospecha; los "humores" más fáciles de templar. ${ }^{64}$

Ahora la estabilidad de los estados desciende de la obediencia de los súbditos y la obediencia se consigue con la virtud del príncipe. Así al centro de una nueva ciencia política se ubica el estudio sistemático de la virtud del príncipe. El jesuita piamontés asumía como horizonte propio el cuadro político de las monarquías, no el de las repúblicas, donde las virtudes residen en los ciudadanos. Las virtudes de los gobernantes son formas de comportamiento en grado de suscitar el amor y la reputación. Las virtudes que conducen al amor de los súbditos se pueden resumir en la justicia y en la liberalidad. Aquellas que aumentan la reputación se resumen en la prudencia política y en el valor. La distancia entre el pensamiento de Botero, nacido en un horizonte italiano, y las teorías políticas de los grandes estados continentales europeos consiste en situar la justicia como materia entre las virtudes a tener en cuenta $y$, en particular, entre las virtudes que procuran el amor de los súbditos. Botero no era jurista y no consideraba que el aparato fundamental del Estado moderno consistiese en la magistratura. Por ello el principio dominante en la teoría boteriana es que la solidez de los estados descansa en que el príncipe ejercite cotidianamente la "prudencia política", que es examinada en el segundo libro. Pero los otros diez libros, los dedica al arte de la guerra, al control del orden interno y a la seguridad externa, y sobre todo a la economía monetaria, agrícola, comercial; es, en definitiva, un examen detallado de los componentes de la prudencia: una prudencia objetiva, un arte de gobierno, también dotado de un carácter de modernidad inusual en los tratados del príncipe. Ha sido observado que Botero cambió la razón de Estado al terreno económico, abriendo así una realidad más avanzada de lo que era el principado maquiaveliano. ${ }^{65}$ El propósito de tener en cuenta la realidad, de no caer en la vacua idealización del príncipe "justo" y por tanto "amado" se puede leer en toda la obra, donde domina una mentalidad práctica y se tiene en cuenta el interés: "La regla general a la cual hay que atenerse en las cuestiones de gobierno, sobre todo en lo referente a la política exterior, es que en política el interés tiene una decidida preponderancia sobre todas las otras consideraciones". ${ }^{66}$ En el libro de Botero hay sólo algu-

\section{Ibídem: 8.}

65 Senellart, M. 1989. Machiavélisme et raison d'Etat. XII $-X V I I I^{e}$ siècle: 56 ss. Paris: PUF. Romain Descendre ha observado recientemente que en Botero "la identificación de la política con el Estado es la condición para una nueva ciencia política, la cual, en el momento mismo en el cual afirma el papel clave del 'secreto' en el proceso de toma de decisiones, se esfuerza... por promover los conocimientos que hacen posible la conservación del dominio, y pronto serán el objeto de las modernas ciencias sociales: poblaciones, riquezas y territorios": Botero G. 2014. De la raison d'Etat (1589-1598), édition, traduction et notes de P. Benedittini et R. Descendre. Introduction: 57. Paris, Gallimard.

66 D'Addio, M. 1984. Storia delle dottrine politiche: I, 516. I, Génova: ECIG. 
nas concesiones al "maquiavelismo" actual: por ejemplo se puede engañar a los heréticos y a los infieles. De hecho, "aquellos que alteran la religión, presionan mucho a la alteración de las cosas, de donde nacen conjuras, sediciones, y camarillas; cosas poco propicias para el principado". ${ }^{67}$ Pero Botero sugería que las cosas de religión se dejaran a los religiosos: “... en cuanto al regimiento, [el Príncipe puede] dejar liberalmente a los Prelados el juicio de la doctrina, y la dirección de las costumbres, y toda esa jurisdicción, que el buen gobierno de las almas busca, y los Cánones, y las leyes les conceden".68 Verá el príncipe que cuando los súbditos sean más educados y devotos serán un tanto más obedientes. La imagen del principado en Botero no es una forma de teocracia, sino que se basa sobre la división de las funciones: el gobierno de la justicia, de la economía y de la guerra corresponde al príncipe; el control de la vida religiosa y moral de los súbditos corresponde a la Iglesia. Justamente Salvo Mastellone consideraba a Botero un portavoz de las solicitudes políticas del orden eclesiástico. ${ }^{69}$

Esta razón de Estado, trasplantada por Botero a su terreno de origen de la política desprejuiciada e inmoral, era entendida como "buena" o "verdadera", mientras fuese moderada en la impostación y dirigida al bien público. A esa se contraponía una "mala" o "falsa" razón de Estado que debe identificarse con la noción corriente del maquiavelismo. Un príncipe religioso, respetuoso del orden eclesiástico y obediente de los preceptos religiosos no tendría necesidad de seguir los preceptos de Tácito y de Maquiavelo.

\section{EL DEBATE ITALIANO Y EUROPEO}

Debemos preguntarnos si la obra de Botero correspondió a la esperanza de monseñor Minucci de tener al fin el libro del príncipe cristiano apto a los tiempos, capaz de desarmar el maquiavelismo de los príncipes y llevar la razón de Estado dentro de los límites tolerables del realismo de la Contrarreforma. Y es preciso decir que no, ya que el fenómeno de la razón de Estado no se podía reducir a un contraste de escuelas doctrinales. El siglo XVI había terminado por convencer que toda la política se reducía "al conjunto de métodos, medios y decisiones" establecidos por los gobiernos sin observar reglas jurídicas y valores morales. ${ }^{70}$ El mismo lenguaje común de la política había sido abandonado, junto al latín, los términos de la "filosofía civil" -respublica, potestas, patria, civitas, civis- para adoptar los nuevos -señoría, Estado, soberanía, príncipe, súbditos, y sobre todo razón de Estado-, de la cual se hablaba hasta en los negocios. ${ }^{71}$

Esta discusión sobre la razón de Estado implicaba la referencia a dos principios, que no son necesariamente

67 Botero, G. 1990: 92.

68 Ibídem: 97.

69 Mastellone, S. 1989: 75-78.

70 Polin, R. 1975. "Le concept de raison d'état", en Schnur, R. (ed.), Staaträson. Studien zur Geschichte eines politischen Begriffs: 30. Berlin: Duncker \& Humbolt.

71 Viroli, M. 1994: X ss., 162 ss. identificables entre ellos: el principio de la racionalidad y el principio de la necesidad. El término "razón" alude a la racionalidad de la acción política, pero el género de comportamiento al cual efectivamente se aludía era aquel inspirado por el Estado de excepción (necessitas legem non habet). ${ }^{72}$ Las teorías orientadas a la racionalidad no consideran la esfera política separada de las otras esferas de racionalidad y no se piensa que se encuentren necesariamente en conflicto con las reglas jurídicas, religiosas, morales. Para ellos la razón de Estado es una ciencia práctica de la política. En cambio, las teorías que se refieren a la razón de necesidad exaltan inevitablemente la cuestión del enfrentamiento frontal que se puede determinar entre las normas ordinarias de conducta y la acción política dirigida a defender al Estado. ${ }^{73}$ En los estados del siglo XVI la regla que admitía excepciones al derecho común frente al estado de excepción se había convertido en praxis ordinaria de gobierno.

La empresa de Botero - de reducir la razón de Estado a ciencia política- estaba en efecto, vinculada a la tradición del racionalismo político aristotélico y tomista que consideraba posible la determinación racional de los fines y confiaba la limitación de los medios a la virtud (para Botero religión+prudencia) del gobernante. Pero la conducta política residual que se había verificado en los hechos (y que a final de cuentas disimulaba el termino ratio, que significaba en realidad calculo de intereses) no escapó a tratadistas sucesivos, los cuales no creían resuelto para siempre el deseo ético que dividía en el mundo moderno el utilitarismo político del derecho y de la moral. ${ }^{74}$ La definición de Botero era en efecto genérica, no desafiaba de forma directa el problema de los límites.

En Italia Girolamo Frachetta fue el primero en retomar la temática de Botero en L'idea del libro de' governi di stato et di guerra... con due Discorsi, l'uno intorno la Ragione di Stato, et l'altro intorno la Ragione di Guerra (Venecia, 1592). Frachetta refutaba que la razón la Estado tuviera estatus de ciencia o de arte política: para él era sobre todo una "disciplina", una forma de educación política del príncipe, compuesta esencialmente de ejemplos históricos y de máximas. ${ }^{75}$ Naturalmente la "verdadera" razón de Estado para él no estaba en contraste con la religión y el derecho. Scipione Ammirato intentó resolver el problema de la razón de Estado en su aspecto de "derogación" del derecho (Discorsi sopra Tacito, 1594), escribiendo que así como la razón civil deroga al derecho natural para hacer posible la comunidad política, la razón de Estado deroga al derecho civil en función de un interés superior, que es el del bien público, la conservación del Estado, no el interés del príncipe. Orientada cada vez más a la "eliminación de los enunciados de los demás, cada tratadista estaba deseoso de hacerse de un lugar para su

\footnotetext{
72 Senellart, M. 1989: 15 ss.

73 Comparato, V. I. 1992. "La ragion di stato: la razionalità politica dell'assolutismo", en N. Matteucci (ed.), L'Italia e la formazione della civiltà europea. La cultura civile: 115 . Turín: UTET.

74 Battista, A. M. 1975. "Morale "privée" et utilitarisme politique en France au XVII siècle", en Schnur, R. (ed.), Staaträson. Studien zur Geschichte eines politischen Begriffs: 87-119. Berlin: Duncker \& Humblot. 75 Baldini, A. E. 1997.
} 
propia formula", ${ }^{76}$ la literatura italiana sobre la razón de Estado se involucró en tortuosas y librescas clasificaciones, incluso porque optar por el terreno resbaloso de la realidad contemporánea era más bien embarazoso. Tratadistas como Ciro Spontone (1599), Antonio Palazzo (1604), Pietro Andrea Canonieri (1614) disputaban sobre el límite de la discrecionalidad que todo príncipe posee en cuanto autor de las leyes, y en general indicaban la esfera jurídica que supera y comprende cada esfera: de derecho divino y natural. Así el príncipe supera el derecho común, pero no viola la religión y la honestidad. ${ }^{77}$ Más interesante aún parece la solución ofrecida en 1621 por Ludovico Zuccolo en Considerationi politiche, e morali sopra cento oracoli d'illustri personaggi antichi, Venecia 1621 -recuperada en 1627 por Ludovico Settala- el cual, sintetizando con mucha precisión lo que otros escritores habían ya observado confusamente, afirmó la imposibilidad de hablar de una única razón de Estado. Todo Estado, en realidad, persigue la política necesaria a su propia constitución. Habrá entonces una razón de Estado monárquica y una republicana, una oligárquica y una tiránica. El juicio sobre la buena y la mala razón de Estado se traduce en una buena o mala forma de gobierno. En el fondo, Zuccolo indicaba una vía para retomar la discusión sobre la ciencia política de los estados, dejando de lado la cuestión de la "verdadera" razón de Estado, que había llegado a un impasse insuperable. Una de las últimas intervenciones en la materia, fue la de Scipione Chiaramonti, que concluyó esta tendencia a la dispersión de la noción originaria, frente a la dificultad de identificar la razón de Estado con la justicia y la prudencia. ${ }^{78}$ Ahora bien, la evidencia demuestra que existen muchos casos diversos, y también la simulación y el engaño, que Chiaramonti incluyó en su minuciosa clasificación Della ragione di stato (Florencia, 1635). Así, en el fondo, los tratadistas italianos de la razón de Estado, "debían... confesar que la que en el uso común era conocida bajo ese nombre, era la mala doctrina, la que permitía al príncipe perseguir su propio interés con cualquier medio, aunque deshonesto". ${ }^{79}$ Los escritores se esforzaban por neutralizar la "falsa" razón de Estado construyendo entorno una red de límites, los cuales, no pudiendo ser jurídicos en el régimen del principado, eran religiosos y morales. $Y$ así, en definitiva, se mostraban dispuestos a convivir con la "verdadera", aunque si no del todo "buena" razón de Estado.

Sin embargo, había también, quien no aceptaba el status quo: en la sombra de una vida transcurrida como funcionario pontificio, un espíritu observador e intolerante del clima de la contrarreforma como Traiano Boccalini (1556-1613) miraba con una actitud completamente distinta al compromiso entre la política y la moral. Sus Ragguagli di Parnaso, publicados no por casualidad en Venecia, en 1612, denotan una exigencia moral, un deseo de transparencia y de rigor muy raro en la literatura política de su tiempo. Moviendo y

\footnotetext{
76 Ibídem: 174-175.

77 De Mattei, R. 1979. Il problema della "Ragion di Stato" nell'età della Controriforma: 92. Milán-Nápoles: Ricciardi.

78 Croce, B. 1967. Storia dell'età barocca in Italia: pensiero, poesia e letteratura, vita morale: 93. Bari: Laterza.

79 Meinecke, F. (1924) 1970. L'idea della ragion di stato nella storia moderna: 120. Florencia: Sansoni.
}

haciendo hablar a personajes antiguos y modernos sobre el falso escenario de la corte de Apolo, Boccalini pinta en términos severos a su siglo y los principios políticos que lo gobiernan. En el primer pasaje de la primer centuria Boccalini abre el ideal fondaco dei Politici, donde se ven los instrumentos de la política corriente. Ahí se encuentra la borra, que amortigua la dureza de la montura a la que se someten aquellos que viven en la corte; pinceles que sirven a los príncipes para "pintar a los pueblos el blanco y el negro", caramelos para perfumar el aliento de los secretarios, consejeros y senadores de las repúblicas obligados a dejar que se "consuman los secretos en el cuerpo"; los lentes que ayudan a no ver "cosas tan desagradables" y muchos otros géneros útiles para hacer tragar grandes trozos, y ayudar a los cortesanos a digerir "amargos disgustos". ${ }^{0}$ En un pasaje sucesivo Seneca es obligado a ceder la mano a Tácito, como por otra parte, hacen también, las ciencias morales, "en los presentes infelicísimos tiempos... consideradas mera pedantería y cosas mohosas", ceden a la política en el siglo actual, en "el cual todo es interés, todo es violencia". ${ }^{81}$ Boccalini presenta a la "mala" razón de Estado como la única efectivamente existente. En su radical pesimismo, la política es para Boccalini irremediablemente corrupta por la costumbre universal, inspirada en el engaño y la disimulación.

El libro de Giovanni Botero, editado más veces en italiano y traducido al español, francés y latín entre finales del siglo XVI y los primeros años del siglo XVII, ${ }^{82}$ se convirtió en el principal vehiculo de difusión de la ciencia política italiana. Hubo traducciones también de Scipione Ammirato, Giovanni Antonio Palazzo, Girolamo Frachetta, Ludovico Settala, Ludovico Zuccolo y Scipione Chiaramonti. ${ }^{83}$ Los Ragguagli de Traiano Boccalini, tuvieron 35 traducciones $^{84}$ y un éxito aún mayor. ${ }^{85} \mathrm{~A}$ partir de finales del siglo XVI la expresión equivalente a la italiana se impuso en las lenguas nacionales, ya sea en los títulos de las obras, o en el uso común: era un signo y no sólo un término y un concepto, sino la realidad subyacente a ellos era perfectamente perceptible en la vida política de los estados europeos. Como había observado Boccalini, era el siglo de la apariencia, de la fuerza y del interés, y por todas partes había que lidiar con la disimulación, la política del poder y los secretos de Estado.

El texto de Botero fue bien conocido en el área germánica, ${ }^{86}$ donde, por todo el siglo XVII, se difundió una tratadística densa y, como había sucedido en Italia, frecuentemente también pedante. En Alemania, de hecho, gran parte de los escritores políticos provenían de las universidades y la razón de Estado había sido insertada,

\footnotetext{
80 Boccalini, T. (1612) 1669. Ragguagli di Parnaso: I, 1, 2-3. Amsterdam: Blaeu.

81 Ibídem: I, 23,74.

82 Firpo, L. 1990: 12.

83 Bozza, T. 1949: passim.

84 Firpo, L. 1965. Traduzioni dei 'Ragguagli' di Traiano Boccalini. Florencia: Sansoni.

85 Hendrix, H. 1995. Traiano Boccalini fra erudizione e polemica. Ricerche sulla fortuna e bibliografia critica: cap. 2, "La storia editoriale", 17-61. Florencia: Olschki.

86 Stolleis, M. 1993. "La scoperta della ragion di Stato: Giovanni Botero in Germania". II Pensiero Politico XXVI: 177-188.
} 
como ciencia específica de los arcana imperii en los cursos de prudentia civilis (Hermann Conring hizo una reseña en 1639: Dissertatio de natura, ac optimis auctoribus civilis prudentiae). Se pueden recordar, entre las obras más importantes, el Discursus politicus de Jakob Bornitz (1602), De arcanis rerumpublicarum libri VI de Arnold Clapmar (1605), Politicorum libri duo de Christoph Besold (1618), Politicorum libri decem del jesuita Adam Contzen (1621) y el Manuale politicum de ratione status del consejero imperial von Efferen (1630). ${ }^{87}$ Mientras en Italia la literatura sobre la razón de Estado estaba declinando, en Alemania continuó hasta fin de siglo. Los autores alemanes recogieron sustancialmente el programa de conciliación entre política y moral que estaba en el corazón de la razón de Estado de la Contrarreforma, dejando poco espacio al "maquiavelismo", con la única excepción de Caspar Schoppe (Paedia politices, 1622), que no dudó en inspirarse directamente en las máximas del Príncipe de Maquiavelo. ${ }^{88}$

Más estrechas fueron las relaciones entre la cultura política italiana y la española, sobre todo en los años de la batalla contra los politiques, de la cual Pedro de Rivadeneira fue uno de los campeones, con el Tratado de la religión y virtudes que debe tener el príncipe cristiano para gobernar y conservar sus estados, contra lo que Nicolás Maquiavelo y los políticos desde tiempo enseñan, Madrid, $1595 .{ }^{89}$ Con Rivadeneira inicia una corriente de pensamiento definida "tradicionalista", que comprende también a El gobernador christiano de Juan Márquez (1612), Diez lamentaciones de Jerónimo Gracián (1611) y la Política de Dios de Francisco de Quevedo (1626-1655). ${ }^{90}$ Fue muy popular, entonces, el tacitismo, a través del cual también el pensamiento político español tenía en cuenta esa área de la política irreducible al modelo del gobernante cristiano. El fundador del tacitismo fue Baltasar Alamos de Barrientos, Aforismos al Tácito español (1614), ${ }^{91}$ al cual siguieron autores como Lorenzo Ramírez de Prado con su obra Consejo y consejeros de príncipes (1614), Juan Antonio de Vera y Zúñiga, El Embajador (1620), Antonio de Herrera, traductor de Botero y Tácito, Discursos, (ms), y sobre todo Diego Saavedra Fajardo, autor de la Idea de un príncipe cristiano representada en cien

87 Véase: Stolleis, M. 1990. Staat und Staaträson in der fruhen Neuzeit. Studien zur Geschichte des öffentlichen Rechts. Frankfurt a/M.: Suhrkamp.

88 D’Addio, M. 1962. Il pensiero politico di Gaspare Scioppio e il machiavellismo del Seicento, Milán: Giuffrè.

89 Para una consideración sobre la influencia de Botero en la política en España en la edad de la Contrarreforma: Gil Pujol, X. 2000. "La razón de Estado en la España de la Contrarreforma. Usos y razones de la política”, en S. Rus Rufino y otros (eds.), La razón de Estado en la España moderna: 37-58. Valencia: Real Sociedad económica de Amigos del País; Idem, 2003. "Las fuerzas del Rey. La generación que leyó a Botero", en M. Rizzo, J. J. Ruiz Ibanez y G. Sabatini (eds.), Le forze del principe. Recursos, instrumentos y límites en la práctica del poder soberano en los territorios de la monarquía hispánica: 971-1022. Universidad de Murcia.

90 Fernández-Santamaría, J. A. 1992. "Botero, Reason of State and Political Tacitism in the Spanish Baroque", en A. E. Baldini (ed.), Botero e la Ragion di Stato. Atti del convengo in memoria di Luigi Firpo: 266-267. Florencia: Olschki.

91 Sobre Alamos cfr. el 'estudio preliminar' de J. A. FernándezSantamaría, en Alamos de Barrientos, B. 1987. Aforismos al Tácito español. Madrid: Centro de Estudios Constitucionales. empresas (1640). Los escritores que trataron directamente el tema de la razón de Estado se pueden dividir en dos tendencias distintas: una que, en sintonía con el propósito de Botero miraba a la fundación de una nueva ciencia política; en ese sentido recuérdese a Sancho de Moncada, que publicó la obra: Restauración política de España (1619); y otra que comprende la mayor parte de los arbitristas del siglo XVII y culmina en El héroe de Baltasar Gracián (1637), inclinado a considerar la política meramente un arte, confiado a la prudencia del príncipe, y por lo tanto a acoger la razón de Estado en su versión desencantada y maquiavélica. ${ }^{92}$

En Francia la tradición política del absolutismo, con su obra de referencia más madura, la République de Jean Bodin, hizo que se prescindiera de Tácito y de Botero. El tacitismo francés fue un fenómeno más tardío, inaugurado por las Observations... sur Tacite de Colomby (1613), pero sobre todo vinculado a la edición francesa y comentada de Tácito de parte de Jean Baudin (1619). A pesar de la traducción de Gabriel Chappuys de 1599, la obra de Botero, con su modelo de principado mezzano que busca sobretodo la conservación, no había sido hecha sobre medida para la mayor monarquía continental, con tendencias expansivas sobre el plan internacional. A pesar de todo, el concepto "razón de Estado" se debatió sin recurrir mucho a los tratadistas italianos, y se convirtió en un argumento polémico en el conflicto político entre los bons français (partidarios del poder monárquico) y los devots (católicos ultramontanos). En las fases de afirmación del poder central -con Enrique IV y después con Richelieu- la literatura política se orientaba hacia los temas del realismo político. En los periodos de debilidad de la monarquía, los católicos "devotos" volvía a discutir la necesidad de armonizar la política con la religión, esto es, con la Curia romana. Las fuerzas contrarias al programa de centralización de Richelieu fueron particularmente activas, entre 1631 y 1637, al denunciar la raison d'enfer que inspiraba las acciones del cardinal e instaba a ignorar por completo los preceptos religiosos..$^{93}$ Era evidente que Richelieu anteponía los intereses nacionales franceses a los intereses de la Iglesia y de la Curia romana: Le Catholique d'état (1625), había sido casi el manifiesto programático; y sucesivamente Hay du Chatelet con sus pamphlets, Jean de Silhon con su Le ministre d'état (1631), Guez de Balzac con Le Prince, (1631), Cardin Le Bret con De la souveraineté du roi (1632) sostenían al unísono que la utilidad pública -entendida como interés del Estado- debía prevalecer sobre cualquier otra consideración. ${ }^{94}$ La razón de Estado de Richelieu, que insiste mucho sobre el carácter racional de la acción del gobierno, se configura como una forma de inteligencia global concerniente a la sociedad, que responde sólo al criterio de la utilidad del Estado. La razón de Estado es administrada entonces no más directamente y

92 Fernández-Santamaría, J. A. 1983. Reason of State and Satecraft in Spanish Political Thought, 1595-1640. Lahnham-New York-London: University Press of America: 293-296.

93 Thuau, E. 1966. Raison d'Etat et pensée politique à l'époque de Richelieu: 103 ss. Paris: A. Colin.

94 Ibídem: 260. 
exclusivamente por el príncipe, sino por el primer ministro y sus agentes: es la ciencia y la práctica de un aparato.

Así la Europa absolutista del siglo XVII comenzaba a dejar de lado, sin tratar de resolver, el problema ético. Todo Estado se mueve según el criterio del interés, en el ámbito interno y en la política internacional. La verdad que la práctica diplomática reconocía ya desde hacía tiempo encontró su expresión completa en la obra del duque de Rohan, De l'interet des princes et états de la Chrétienté (1639), resultado de las tantas "relaciones" de las cuales se nutría la actividad diplomática, y a su vez modelo de sucesivas y numerosas reseñas de política internacional. La razón de Estado italianizante y "maquiavélica" que todos los comentaristas de la Contrarreforma habían intentado domesticar era evocada en el mismo año por Gabriel Naudé -secretario del candidato francés al pontificado, el cardenal Guidi di Bagno- en una edición clandestina titulada Considérations politiques sur les coups d'état. Era un obra escrita en la Roma barberiniana, teatro de manobrias diplomáticas de los embajadores de todos los estados católicos: un texto de escritura refinada, pero también de provocativa franqueza al enumerar los crímenes realizados por los gobiernos en nombre del interés del Estado. Naudé no intentó juzgarlos bajo el perfil moral o religioso: la eficacia de la acción política se había convertido en el único criterio para juzgar la política.

\section{CONCLUSIÓN}

La historia de la escritura política del siglo XVII se movió sobre diferentes registros. En parte heredó el profundo conflicto -que había intentado reconstruir el siglo precedenteentre la esfera religiosa y moral y la esfera práctica y real; en parte, ésta estuvo influenciada por el cambio ya sea de contextos políticos como de conceptos filosóficos. Por lo tanto, la alternativa entre realismo y aspiración a la sociedad justa y al gobierno virtuoso siguió presentándose, pero en el contexto dramático del siglo XVII, que puso bajo los ojos de los observadores políticos guerras y revoluciones. Desde el punto de vista de la filosofía política, el advenimiento de lo que llamamos "teoría del derecho natural moderno", sin interrumpir la continuidad temática con el contractualismo de Vitoria, Mariana y Suárez, marcó la transición del rico y complejo conjunto de instrumentos disponibles para comprender y gestionar lo existente a la pregunta filosófico-política primaria sobre el origen y el fin de la sociedad civil. Comenzaba la era de la indagación racional y científica y aquel de los derechos individuales, no más fundados en la tradición, o garantizados por la tutela eclesiástica, sino surgidos de los caracteres propios de una legítima sociedad civil. Así, en nombre de la racionalidad, mientras por una parte, se continuaba con el programa político centralizador del Estado moderno, se fortalecían también los instrumentos intelectuales (la búsqueda de la "libertad filosófica") y la eficacia de modelos políticos antiguos y contemporáneos, destinados a poner en crisis la idea de la "naturalidad" del gobierno monárquico y la primacía de la obediencia entre las virtudes políticas.

\section{BibLIOgRAFÍA}

Fuentes

Albergati, F. 1664. De i discorsi politici... libri cinque ne i quali viene riprovata la dottrina politica di Gio. Bodino, e difesa quella d'Aristotile. Roma: Giacomo Dragondelli.

Ammirato, S. 1642. Discorsi... sopra Cornelio Tacito. Padua: per Paolo Frambotto.

Bellarmino, R. 1610. Tractatus de potestate Summi Pontificis in rebus temporalibus adversus Gulielmum Barclaium. Roma: Zannetti.

Boccalini, T. (1612) 1669. Ragguagli di Parnaso. Amsterdam: Blaeu.

Bodin, J. 1951. Methodus ad facilem historiarum cognitionem, en Oeuvres philosophiques, P. Mesnard (ed.) Paris: PUF.

Bodin, J. 1964-1997. I sei libri dello stato, 3 voll., M. Isnardi Parente y D. Quaglioni (ed.) Turín: UTET.

Botero, G. 1990. Della ragion di stato e Delle cause della grandezza delle città, Bolonia: Forni. (reprint de la ed. De Venecia, 1598).

Campanella, T. 1956. Discorsi universali del governo eclesiástico per far una gregge e un pastore, en A. Guzzo y R. Amerio (ed.) Opere di Giordano Bruno e Tommaso Campanella. Milán-Nápoles: Ricciardi.

Campanella, T. 1962. La città del sole e scelta di alcune poesie filosofiche, A. Seroni (ed.) Milán: Feltrinelli.

Campanella, T. 1995. La monarchia del Messia, V. Frajese (ed.) Roma: Edizioni di Storia e Letteratura.

Capaccio, G. C. 1597. I/ Secretario.... Venecia: Nicolò Moretti.

Contarini, P. M. 1990. Compendio universal di republica, V. Conti (ed.) Florencia: CET.

Davila, E. C. 1683. Historia delle guerre civili di Francia. Venezia: Prosdocimo.

Di Castro, S. 1978. La politica come retorica, R. Zapperi (ed.) Roma: Istituto della Enciclopedia Italiana.

Gracián, B. 1987. L'eroe e il saggio, A. Gasparetti (ed.) Parma: Guanda.

Garzoni, T. 1589. La piazza universale di tutte le professioni del mondo nuovamente ristampata... Venecia: G.B. Somasco.

Guazzo, S. 1993. La civil conversazione. A. Quondam (ed.) Ferrara: Panini.

Guicciardini, F. 1990. Ricordi, V. De Caprio (ed.) Roma: Salerno.

Lipsius, J. 1589. Politicorum sive civilis doctrinae libri sex, Lugduni Batavorum: ex officina Plantiniana.

Lipsius, J. 2012. Opere politiche. vol. I, La Politica. T. Provvidera (ed.) con un ensayo de M. Fumaroli. Turín: Nino Aragno.

Lottini, G. 1941. Avvedimenti civil. G. Mancini (ed.) Bolonia: Zanichelli. 
Montaigne, M. De 1962. Essais, en Oeuvres complètes. III. 8. Paris: Gallimard.

Naudé, G. 1958. Considerazioni politiche sui colpi di stato. Turín: Boringhieri.

Paruta, P. 1964. Della perfezione della vita politica, en Scrittori politici del '500 e ‘600, B. Widmar (ed.) Milán: Rizzoli.

Paruta, P. 1943. Discorsi politici nei quali si considerano diversi fatti illustri e memorabili di principi e di repubbliche antiche e moderne divisi in due libri, G. Candeloro (ed.) Bolonia: Zanichelli.

Patrizi, F. 1930. La città felice, en Scrittori politici del '500 e '600. B. Croce y S. Carmella (eds.) Bari: Laterza.

Richelieu. 1988. Testamento politico e massime di stato. G. Piazzi (ed.) Milán: Giuffrè.

Rohan, H. de. 1638. De l'interest des Princes et estats de la Chrestienté. Paris: Courbé.

Scrittori politici del '500 e '600. B. Widmar (ed.) Milán: Rizzoli, 1964.

Zuccolo, L. 1930. Considerazioni politiche e morali sopra cento oracoli d'illustri personaggi antichi, en Politici e moralisti del Seicento. Bari: Laterza.

\section{Ensayos}

El instrumento bibliográfico para la historia de la Razón de Estado es la bibliografía boteriana publicada por A. E. Baldini Botero e la Ragion di Stato. Atti del convengo in memoria di Luigi Firpo (Turín, 8-10 marzo 1990), 503-553. Florencia: Olschki 1992.

Ambrosetti, G. 1951. I/ diritto naturale della Riforma cattolica. Milán: Giuffrè.

Baldini, A. E. 1989. "Le guerre di religione francesi nella trattatistica italiana della ragion di Stato: Botero e Frachetta". II Pensiero Politico XXI: 301-234.

Baldini, A. E. (ed.) 1995. Aristotelismo politico e ragion di stato. Atti del convengo internazionale di Torino. 11-13, 1993. Florencia: Olschki.

Baldini, A. E. 1995. "Aristotelismo e platonismo nelle dispute romane sulla ragion di Stato di fine Cinquecento", en Aristotelismo politico e ragion di stato. Florencia: Olschki.

Baldini, A. E. y A. M. Battista. 1997. "Il dibattito politico nell'Italia della Controriforma: Ragion di Stato, tacitismo, machiavellismo, utopia." I/ Pensiero Politico XXX: 393-439.

Baldini, A. E. 2001. "Ragion di Stato, Tacitismo, Machiavellismo e Antimachiavellismo tra Italia ed Europa nell'età della Controriforma. Bibliografia (1860-2001)", en A. E. Baldini (ed.) La ragion di Stato dopo Meinecke e Croce. Dibattito su recenti pubblicazioni. Atti del convegno internazionale di Torino 21-22 ottobre, 1994. 2. ed. aggiornata, Génova: Name.

Baldini, A. E. 2014. "Aspetti storici e teorici del Machiavellismo", en G. Lencan Stoica, S. Drăgulin (coord.) Noi studii asupra lui Machiavelli și machiavelismului. Abordări și istoriografie. Bucuresti: Editura Ars Docendi.
Barcia, F. 1996. Salvatore Cadana. Diplomazia e ragion di stato alla corte dei Savoia (1597-1664). Milán: Angeli.

Battista, A. M. 1966. Alle origini del pensiero politico libertino. Montaigne e Charron. Milán: Giuffrè.

Battista, A. M. 1975. "Morale "privée" et utilitarisme politique en France au XVII siècle", en Schnur, R. (ed.) Staaträson. Studien zur Geschichte eines politischen Begriffs. Berlin: Duncker \& Humblot.

Birely, R. 1990. The Counter-Reformation Prince. AntiMachiavellianism or Catholic Statecraft in Early Modern Europe. Chapel Hill and London: The University of North Carolina Press.

Bock, G., Q. Skinner y M. Viroli (eds.) 1990. Machiavelli and Republicanism. Cambridge: University Press.

Borrelli, G. 1993. Ragion di Stato e Leviatano. Conservazione e scambio alle origini della modernità política. Bolonia: II Mulino.

Bouwsma, W. J. 1977. Venezia e la difesa della libertà repubblicana. I valori del Rinascimento nell'età della Controriforma. Bolonia: il Mulino.

Bozza, T. 1949. Scrittori politici italiani dal 1550 al 1650. Roma: Edizioni di Storia e Letteratura.

Church, W. F. 1972. Richelieu and Reason of State, Princeton: University Press.

Comparato, V. I. 1986. "Il pensiero politico europeo dalla "ragion di stato" all'illuminismo", en M. Firpo y N. Tranfaglia (eds.) La storia. I grandi problemi dal Medioevo all'età contemporánea: 99-633. Turín: UTET.

Comparato, V. I. (ed.) 1987. Modelli nella storia del pensiero politico. Florencia: Olschki.

Comparato, V. I. 1992. "La ragion di stato: la racionalita politica dell'assolutismo", en N. Matteucci (ed.) L'Italia e la formazione della civiltà europea. La cultura civile, Turín: UTET.

Comparato, V. I. y D. Quaglioni. 2007. Italy. en European Political Thought 1450-1700. Religion, Law and Philosophy: 55-101. Yale University Press.

Comparato, V. I. 2013. "Readers of Bodin in Italy. From Albergati to Filangieri", en Howell A. Lloyd (ed.) The reception of Bodin. Leiden: Brill.

Convegno di studi in onore di Lodovico Zuccolo nel quarto centenario della nascita. 1969. Faenza: Lega.

Corsano, A. 1961. Tommaso Campanella. Bari: Laterza.

Costantini, C. 1978. La repubblica di Genova nell'età moderna, Turín: UTET.

Crahay, R. 1981. "Jean Bodin devant la censure: la condamnation de la 'République'". II Pensiero Politico XIV: 154-172.

Crahay, R. 1993. Un intellectuel ecclésiastique au XVII siècle: Tommaso Campanella. Perugia: Dipartimento di scienze storiche.

Cristianesimo e ragion di stato. Atti del II Congresso Internazionale di Studi Umanistici. E. Castelli (ed.) 1953. Roma-Milán: Bocca. 
Croce, B. 1967. Storia dell'età barocca in Italia. PensieroPoesia e letteratura-Vita morale. Bari: Laterza.

Culture et idéologie dans la genèse de l'état moderne.1985. Roma: Ecole Française.

D’Addio, M. 1962. Il pensiero politico di Gaspare Scioppio e il machiavellismo del Seicento. Milán: Giuffrè.

D’Addio, M. 1984. Storia delle dottrine politiche. I, Génova: ECIG.

D’Alessio, S. 2006. "Per una nuova scienza. Medicina e politica nella prima età moderna", en Biopolitiche: 265-292. Avellino: Sellino.

D’Alessio, S. 2015. Per un principe "medico publico». Il percorso di Pietro Andrea Canoniero. Florencia: Centro Editoriale Toscano.

De Mattei, R. 1969. Dal premachiavellsimo all'antimachiavellismo. Florencia: Sansoni.

De Mattei, R. 1979. Il problema della "Ragion di Stato" nell'età della Controriforma. Milán-Nápoles: Ricciardi.

De Mattei, R. 1982-84. Il pensiero politico italiano nell'età della Controriforma. Milán-Nápoles: Ricciardi, 2 vols.

Di Castro, S. 1978. La politica come retorica. R. Zapperi (ed.) Roma: Istituto della Enciclopedia Italiana.

Dominique, P. 1955. La politique des Jésuites. Paris: Grasset.

Donati, C. 1988. L'idea di nobiltà in Italia. Secoli XIV-XVIII. Roma-Bari: Laterza.

Durand, Y. 1973. Les républiques au temps des monarchies. Paris: PUF.

Ernst, G. 1991. Religione, Ragione e Natura. Ricerche su Tommaso Campanella e il tardo Rinascimento. Milán: Angeli.

Fassò, G. 1968. Storia della filosofia del diritto. vol. II, L'età moderna, Bolonia: II Mulino.

Fernández-Santamaría, J. A. 1983. Reason of State and Statecraft in Spanish Political Thought, 1595-1640. Lahnham-New York-London: University Press of America.

Fernández-Santamaría, J. A. 1987. "Estudio preliminar". en B. Alamos de Barrientos, Aforismos al Tácito español, Madrid: CEC.

Fernández-Santamaría, J. A. 1992. "Botero, "Reason of State and Political Tacitism in the Spanish Baroque", en A. E. Baldini (ed.) Botero e la Ragion di Stato. Atti del convengo in memoria di Luigi Firpo, Florencia: Olschki.

Firpo, L. 1947. Ricerche campanelliane. Florencia: Sansoni.

Firpo, L. 1957. Lo stato ideale della Controriforma. Ludovico Agostini. Bari: Laterza.

Firpo, L. 1964. "Il pensiero politico del Rinascimento e della Controriforma", en Grande antologia filosofica, X, II pensiero della Rinascenza e della Riforma, Milán: Marzorati.

Firpo, L. 1965. Traduzioni dei "Ragguagli" di Traiano Boccalini, Florencia: Sansoni.

Firpo, L. 1969. “Le origini dell'antimachiavellismo, en Machiavellismo e antimachiavellici nel Cinquecento". Atti del convegno di Perugia. II Pensiero Politico II-3.
Firpo, L. 1974. “Campanella Tommaso”, en Dizionario biografico degli italiani. XVII: 372-401.

Firpo, L. 1981. "Ancora sulla condanna di Bodin." II Pensiero Politico XIV: 173-186.

Firpo, L. 1990. La "Ragion di Stato" di Giovanni Botero. Redazione, rifacimenti, fortuna", en G. Botero. Della ragion di stato e Delle cause della grandezza delle città. Bolonia: Forni, (reprint de la ed. de Venecia, 1598).

Hendrix, H. 1995. Traiano Boccalini fra erudizione e polemica. Ricerche sulla fortuna e bibliografia critica. Florencia: Olschki.

Lazzeri, Ch. y D. Reynié. 1992. La raison d'état: politique et rationalité. Paris: PUF.

Machiavelli, N. 1990. Istorie fiorentine, en Opere, C. Vivanti (ed.) libro VII, Torino: Einaudi.

Machiavellismo e antimachiavellici nel Cinquecento. Atti del convengo di Perugia. II Pensiero Politico. 1969. II-3.

Maravall, J. A. 1991. Stato moderno e mentalità sociale. Bolonia: Il Mulino. 2 vols.

Marin, L. 1988. "Pour une théorie baroque de l'action politique", en G. Naudé. Considérations politiques sur les coups d'état: 5-65. Paris: Les Editions de Paris.

Mastellone, S. 1962. La reggenza di Maria de' Medici. Florencia: D’Anna.

Mastellone, S. 1969. "Aspetti dell'antimachiavellismo in Francia: Gentillet et Languet", en Machiavellismo e antimachiavellici nel Cinquecento. Atti del convengo di Perugia. II Pensiero Politico: II-3.

Mastellone, S. 1972. Venalità e machiavellismo in Francia, 1572-1610. Alle origini della mentalità politica borghese. Florencia: Olschki.

Mastellone, S. 1980. "Tommaso Bozio teorico dell'ordine ecclesiastico". II Pensiero Politico XIII: 186-194.

Mastellone, S. 1989. Storia del pensiero politico europeo. vol. I. Dal xv al xvIII secolo, Turín: UTET Libreria.

Meinecke, F. (1924) 1970. L'idea della ragion di stato nella storia moderna. Florencia: Sansoni.

Méchoulan, H. (ed.), 1985. L'état baroque 1610-1652. Regards sur la pensée politique de la France du premier XVII siècle. Paris: Vrin.

Münkler, H. 1987. Im Namen des Staates. Die Begrundung der Saatraison in der Frühen Neuzeit. Frankfurt: a/M: Fischer Verlag.

Nuzzo, E. 1995. “Crisi dell'aristotelismo politico e ragion di Stato. Alcune preliminari considerazioni metodologiche e storiografiche", en Baldini, A. E. (ed.) Aristotelismo politico e ragion di stato. Florencia: Olschki.

Oestreich, G. 1982. Neostoicism and the Early Modern State. Cambridge: CUP.

Pocock, J.G.A. 1980. II momento machiavelliano. I/ pensiero politico e la tradizione repubblicana anglosassone. Bolonia: II Mulino.

Polin, R. 1975. "Le concept de raison d'état", en Schnur, R. (ed.) Staaträson. Studien zur Geschichte eines politischen Begriffs, Berlin: Duncker \& Humblot. 
Prodi, P. 1982. Il sovrano pontífice. Un corpo e due anime: la monarchia papale nella prima età moderna, Bolonia: II Mulino.

Prosperi, A. 1996. Tribunali della coscienza. Inquisitori, confessori, missionari, Turín: Einaudi.

Quaglioni, D. 1987. "Il modello del principe cristiano. Gli "specula principum" fra Medioevo e prima Età Moderna", en V. I. Comparato (ed.) Modelli nella storia del pensiero politico, Florencia: Olschki.

Quaglioni, D. 1992. I limiti della sovranità. II pensiero di Jean Bodin nella cultura giuridica e politica dell'età moderna. Padua: CEDAM.

Schiera, P. (ed.) 1996. Ragion di Stato e ragioni dello Stato (secoli XV-XVII). Nápoles: L'officina tipografica.

Schnur, R. (ed.) 1975. Staaträson. Studien zur Geschichte eines politischen Begriffs. Berlin: Duncker \& Humblot.

Sénellart, M. 1989. Machiavélisme et raison d'Etat. XII xVIII siècle. Paris: PUF.

Sénellart, M. 1995. Les arts de gouverner. Du regimen medieval au concept de gouvernement. Paris: Seuil.

Spini, G. 1960. Storia dell'età moderna, II, 1598-1661. Turín: Einaudi.

Stolleis, M. 1990. Staat und Staaträson in der fruhen Neuzeit. Frankfurt a/M.: Suhrkamp.

Stolleis, M. 1993. "La scoperta della ragion di Stato: Giovanni Botero in Germania". II Pensiero Politico XXVI: 177-188.
Taranto, D. 1995. Per un repertorio bibliografico delle scritture politiche italiane della seconda metà del Seicento. en "Archivio della Ragion di Stato" 3: 5-56.

Tenenti, A. 1987. Stato: un'idea, una logica. Dal comune italiano all'assolutismo francese. Bolonia: II Mulino.

Thuau, E. 1966. Raison d'Etat et pensée politique à l'époque de Richelieu. Paris: A. Colin.

Toffanin, G. (1921) 1972. Machiavelli e il "Tacitismo". La "Politica storica" al tempo della controriforma. Nápoles: Guida.

Van Gelderen, M. y Q. Skinner (eds.) 2012. Republicanism: a shared European Heritage. Cambridge University Press, 2 vols.

Vasoli, C. 1987. Francesco Patrizi da Cherso e il "modello" della società dei sacerdoti-sapienti, en V. I. Comparato (ed.). Modelli nella storia del pensiero político. Florencia: Olschki.

Vasoli, C. 1995. "Il carattere "naturale" dello stato e la sua "patologia" nella tradizione politica aristotelica", en Baldini, A. E. (ed.), Aristotelismo politico e ragion di stato, Florencia: Olschki.

Viroli, M. 1994. Dalla politica alla ragion di stato. La scienza del governo tra XIII e XVII secolo. Roma: Donzelli.

Zarka Ch. (ed.) 1994. Raison et déraison d'Etat. Théoriciens et théories de la raison d'Etat au XVI ${ }^{e}$ et XVII siècles. Paris: PUF. 